Article

\title{
Observer Design for Nonlinear Invertible System from the View of Both Local and Global Levels
}

\author{
Mei Zhang ${ }^{1}$, Qinmu Wu ${ }^{1}$, Xiangping Chen ${ }^{1}{ }^{\mathbb{D}}$, Boutaïeb Dahhou ${ }^{2}$ and Zetao $\mathrm{Li}^{1}{ }^{1}$ * \\ 1 Guizhou Provincial Key Laboratory of Internet Plus Collaborative Intelligent Manufacturing, \\ Electrical Engineering School, Guizhou University, Guiyang 550025, China; mzhang3@gzu.edu.cn (M.Z.); \\ qmwu@gzu.edu.cn (Q.W.); ee.xpchen@gzu.edu.cn (X.C.) \\ 2 University de Toulouse, UPS, LAAS, F-31400 Toulouse, France; boutaib.dahhou@laas.fr \\ * Correspondence: ztli@gzu.edu.cn
}

Received: 22 September 2020; Accepted: 4 November 2020; Published: 10 November 2020

check for updates

\begin{abstract}
This paper emphasizes the importance of the influences of local dynamics on the global dynamics of a control system. By considering an actuator as an individual, nonlinear subsystem connected with a nonlinear process subsystem in cascade, a structure of interconnected nonlinear systems is proposed which allows for global and local supervision properties of the interconnected systems. To achieve this purpose, a kind of interconnected observer design method is investigated, and the convergence is studied. One major difficulty is that a state observation can only rely on the global system output at the terminal boundary. This is because the connection point between the two subsystems is considered unable to be measured, due to physical or economic reasons. Therefore, the aim of the interconnected observer is to estimate the state vector of each subsystem and the unmeasurable connection point. Specifically, the output used in the observer of the actuator subsystem is replaced by the estimation of the process subsystem observer, while the estimation of this interconnection is treated like an additional state in the observer design of the process subsystem. Expression for this new state is achieved by calculating the derivatives of the output equation of the actuator subsystem. Numerical simulations confirm the effectiveness and robustness of the proposed observer, which highlight the significance of the work compared with state-of-the-art methods.
\end{abstract}

Keywords: interconnected nonlinear system; states estimation; left invertibility; local dynamics; process subsystem; actuator subsystem; unknown interconnection

\section{Introduction}

A modern system often consists of a series of interconnected dynamical units (sensors, actuators and system components) and, therefore, very complicated dynamics are exhibited [1]. Technological advances mean that these units themselves are dynamic systems and exhibit complicated dynamics. Therefore, a modern control system can be viewed as composed of dynamic subsystems connected in a series. In all situations, the global plant can be analyzed at different levels-down to the component levelto estimate the reliability of the whole plant.

In recent years, the topic of observer design for separate nonlinear systems has been widely discussed in the literature, like high-gain observers [2-4], sliding mode observers [5,6], adaptive observers [7-9], and unknown input observers (UIOs) [10-12]. These methodologies are typically centralized monitoring systems where intelligence is either at the system level or at the field device level of the processing plant. For the former, it aims at monitoring plant dynamics from the viewpoint of a global system, like in [13-15]. In these methods, the dynamics of subcomponents (i.e., actuators) are often neglected. They are, generally speaking, treated as constants in the input or output coefficient matrix (function) of the process system model. For the latter, it focuses on the field device level, 
aiming at analyzing the internal dynamics of a specific subcomponent while the influences of local internal dynamics on the global dynamics are neglected, like in $[3,16]$.

However, centralized observers may not be suitable for modern control systems. On one hand, a modern control system is in fact an interconnected system, while the centralized observer just enables an individual component to monitor internal dynamics locally. However, the dynamics of the field devices can cause significant disturbances to the global process and influence the quality of the final product $[17,18]$. On the other hand, due to uneconomical measurement costs or physical environment factors such as high temperature, it is impossible to measure the state or partial state, such as in $[19,20]$. To overcome these difficulties, an effective way is to decompose the system into several interconnected subsystems so that the observer can be decentralized in each subsystem. In this way, it allows the analysis of less complex subcomponents to study the characteristics of interconnected systems.

The last few decades have also witnessed significant improvements in dynamic networks which consist of a number of interconnected units, like in [1,21-24]. A typical approach is to design distributed observers for each subsystem using the internal information of each subsystem, and then all the observers are aggregated to form the total estimator [25-27]. For instance, in [26], an observer was designed for the whole system from the separate synthesis of observers for each subsystem, assuming that for each of these separate designs, the states from the other subsystem were available. In [27], an observer for each subsystem was proposed, using the state estimation of the previous subsystem. In addition, a quasi-input-to-state stability and input-to-state dynamical stability (ISS/ISDS) reduced-order observer for the whole system was designed, considering the interconnections of quasi-ISS/ISDS reduced-order observers for each subsystem. A major challenge for these methods is the availability of the measurement of the interconnections between subsystems. Therefore, it is interesting to consider the problem of whether we can prove that, under some conditions, the effect in lower subsystems can be distinguished from higher subsystems, thus avoiding full measurements of the local subsystem. For example, in this work, the interconnection is the output of the actuator, and it is not economical or realistic to measure its output. Contributions dealing with the state observation problem for interconnected systems subjected to unknown interconnections have received less extensive treatment in the literature. In [28], a promising method to solve the state observation problem of nonlinear systems modeled by ODE-PDE series was proposed. A similar problem was also studied in [29], where the interconnected system was composed of a nonlinear system and a linear system.

In this paper, the problem of state estimation for interconnected nonlinear dynamic systems is studied. An interconnected system consists of two nonlinear dynamic subsystems, and the interconnection point is unknown. Thus, one major difficulty is that state observation can only rely on the output of the terminal subsystem, making existing observers useless. Therefore, the problem considered here is that the output of the nonlinear system cannot be measured directly, while part of the state measurement of the second nonlinear system can be obtained. Two issues are highlighted here. Firstly, it is assumed that the measurement value used by the observer of the former subsystem is unmeasurable, and the solution is to replace it with the estimated value of the observer of the latter subsystem. Secondly, in the latter subsystem, the estimated interconnection provided for the former subsystem is regarded as an additional state to form a new, extended subsystem. The expression of the new state is obtained by calculating the derivative of the output equation of the former subsystem.

The contribution of this paper mainly lies in its emphasis of the importance of the influences of local internal dynamics (actuator) on the global dynamics of a control system. A method is proposed to distinguish the influence of low subsystems in higher subsystems, even if the full measurement of local subsystems cannot be realized. Thus, the goal of the design methodology is to enable or simplify observer design for systems that are otherwise difficult to handle by allowing the designer to focus on a smaller, nonlinear subsystem. That is to say, we mainly focus on observing, for example, how the change of an internal parameter at the local level affects the global output at the global level. As a 
result, both local and global dynamics supervision is achieved, as well as analysis of the influences of local internal dynamics on the global dynamics.

The rest of the paper is organized as follows. Problem formulation is introduced in Section 2, where the type of dynamic units of the interconnected system is explained, and the main objective is introduced. Section 3 contains all the results for the observer design, with respect to the interconnected systems. Some numerical simulation examples are given to illustrate the effectiveness of the proposed methods in Section 4. Finally, a conclusion is made in Section 5.

\section{Motivations and Problem Formulations}

The problem of state observation is investigated for an interconnected nonlinear system, modeled by two cascaded nonlinear dynamical subsystems: the process and the actuator subsystems. As shown in Figure 1, an interconnected nonlinear system structure is proposed by considering both the actuator and the process as individual dynamic subsystems connected in cascade. The aim is to accurately estimate the state vector of both subsystems, as well as the interconnection. As a result, both local and global dynamics supervision are realized, and analysis of the influence of local internal dynamics on global dynamics is achieved.

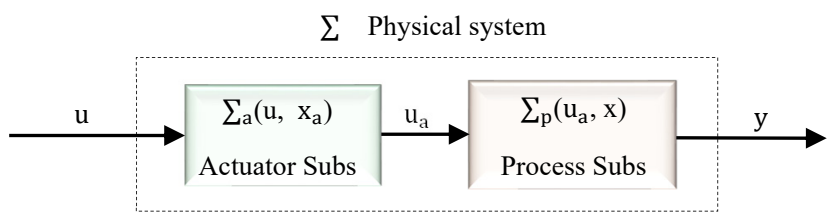

Figure 1. Structure of an interconnected system.

A dynamic process subsystem is proposed in an input affine form:

$$
\Sigma_{p}:\left\{\begin{array}{l}
\dot{x}=f(x)+g(x) u_{a}, \quad x\left(t_{0}\right)=x_{0} \\
y=x
\end{array}\right.
$$

where $\mathrm{x} \in \Re^{\mathrm{n}}$ is the state of the process subsystem, $\mathrm{y} \in \Re^{\mathrm{p}}$ is the output of the global system, which is also the output of the process subsystem, $\mathrm{u}_{\mathrm{a}} \in \Re^{\mathrm{m}}$ is the input of the process subsystem, which is also the output of the actuator subsystem, $u_{a}$ is assumed to be inaccessible, and $f$ and $g$ are smooth vector fields on $\Re^{\mathrm{n}}$.

The actuator subsystem is described as

$$
\Sigma_{a}: \begin{cases}\dot{x}_{a}=f_{a}\left(x_{a}, u\right) & x_{a}\left(t_{0}\right)=x_{a} 0 \\ u_{a}=h_{a}\left(x_{a}, u\right)\end{cases}
$$

where $\mathrm{x}_{\mathrm{a}} \in \Re^{\mathrm{n}}$ is the state, $\mathrm{u} \in \Re^{\mathrm{l}}$ is the input and constant parameter to be monitored, $\mathrm{u}_{\mathrm{a}} \in \mathrm{R}^{\mathrm{m}}$ is the output of the actuator subsystem, which is also the input of the process subsystem, $\mathrm{f}_{\mathrm{a}}$ is the smooth vector field on $\Re^{\mathrm{n}}$, and $\mathrm{h}_{\mathrm{a}}$ is the smooth vector field on $\Re^{\mathrm{m}}$.

Considering the interconnected system described by Equations (1) and (2), it is required to monitor the performance of the interconnected system from the perspective of a single subsystem and the whole system; that is, it is required to describe the cause and effect relationships between the subsystem variables and global system output $y$, thus providing advanced predictive maintenance techniques in an operating plant. The left invertibility of the interconnected system is then required for ensuring that the impact of local variables on the global level is distinguishable. The property of distinguishability of the two inputs or parameters refers to their capacity to generate different output signals for a given input signal. 
One way to achieve this purpose is to propose observers for each of the subsystems and the whole network. However, the main difficulty is that the connection point between the two subsystems cannot be measured. This is because the interconnection point is the output of the actuator subsystem, and online measurement is difficult to achieve due to physical or uneconomical reasons. In addition, the measured value could be unreliable, due to its rough operation environment.

Therefore, the state observation in this work can only rely on the global system output (i.e., the process state at the terminal boundary). As shown in Figure 1, the particular aim of our design is to accurately estimate the state vectors $x$ and $x_{a}$ of each subsystem online, as well as the unmeasured interconnection vector $\mathrm{u}_{\mathrm{a}}$.

\section{Observer Design}

The structure of the proposed interconnected observer is shown in Figure 2. It is a two-stage interconnected observer system, consisting of an actuator and a process state estimator. The actuator state estimator deals with estimating the states of the actuator subsystem, where the major challenge is that the output is inaccessible. Aiding the actuator, the process state estimator is a coordinator that extends the interconnection as an additional state of the process subsystem. This process state estimator generates an input sequence which is applied to the actuator subsystem. Then, the overall observer estimates the states and interconnections of the interconnected system by using the estimates of the two estimators.

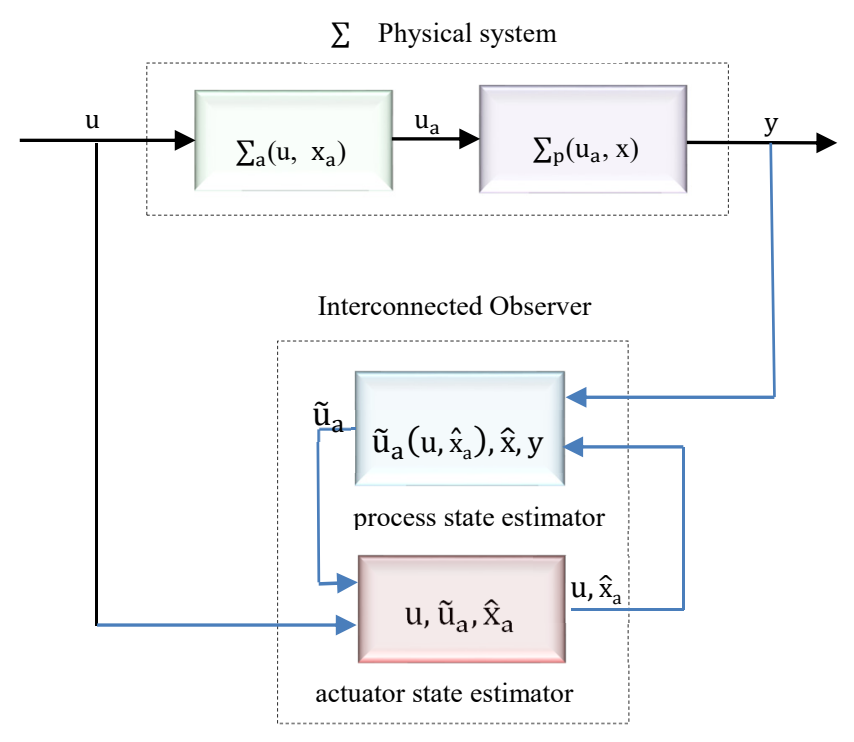

Figure 2. Structure of the proposed interconnected observer.

The main idea of the interconnected observer design is as follows. In the first aspect, the unknown interconnection is extended as new states of the process subsystem, where the expression can be achieved via derivatives of the output expression of the actuator subsystem, thus forming a new process subsystem. Then, for the state estimation of each subsystem of the interconnected system, the state estimation of one subsystem is realized by the state estimation of the other subsystem, and the global estimator is formed by the set of both observers. Specifically, it is assumed that an existing observer is already available for the actuator subsystem $\sum_{a}$, where the measured output is $\mathrm{u}_{\mathrm{a}}$, while the observer is implemented using an estimate of $\mathrm{u}_{\mathrm{a}}$, denoted by $\widetilde{\mathrm{u}}_{\mathrm{a}}$. In order to obtain this estimate, the state space of the process subsystem $\sum_{p}$ is extended to include $u_{a}$ as an additional state. By calculating the derivatives of the value $u_{a}$ of the actuator subsystem, the expression of the time derivatives of $u_{a}$ is obtained; it is a function of $u$, with derivatives of $u$ and $x_{a}$. In summation, for the studied interconnected nonlinear systems, an interconnected observer design method is proposed by combining both actuator and process subsystem state estimators. 


\subsection{Observer Design for the Interconnected System}

\subsubsection{Interconnected System Extension}

For the interconnected system described by Equations (1) and (2), in order to facilitate analysis, the unknown interconnection $\mathrm{u}_{\mathrm{a}}$ is extended as a new state $\mathrm{x}_{\mathrm{u}}$ :

$$
\left\{\begin{array}{l}
\mathrm{x}_{\mathrm{u}}: \triangleq \mathrm{u}_{\mathrm{a}} \\
\dot{\mathrm{x}}_{\mathrm{u}}:=\dot{\mathrm{u}}_{\mathrm{a}}
\end{array}\right.
$$

To get a function for $\dot{x}_{u}$, inspired by the work proposed in [29], let us derivate the output $u_{a}$ in Equation (2) to get the following function:

$$
\dot{\mathrm{x}}_{\mathrm{u}}:=\dot{\mathrm{u}}_{\mathrm{a}}=\varepsilon\left(\mathrm{u}, \dot{\mathrm{u}}, \mathrm{x}_{\mathrm{a}}\right)=\frac{\partial \mathrm{h}_{\mathrm{a}}}{\partial \mathrm{u}}\left(\mathrm{u}, \mathrm{x}_{\mathrm{a}}\right) \dot{\mathrm{u}}+\frac{\partial \mathrm{h}_{\mathrm{a}}}{\partial \mathrm{x}_{\mathrm{a}}}\left(\mathrm{u}, \mathrm{x}_{\mathrm{a}}\right) \mathrm{f}_{\mathrm{a}}\left(\mathrm{u}, \mathrm{x}_{\mathrm{a}}\right)
$$

where the function $\varepsilon\left(u, \dot{u}, x_{a}\right)$ is with respect to the time derivative of the output $u_{a}$ in Equation (2).

We can define Assumption 1 as follows: For any function $\mathrm{u} \in \mathcal{U}\left(\mathrm{t}, \hat{\mathrm{x}}_{\mathrm{a}}\right) \in \mathcal{A} \cdot \mathcal{C}\left(\Re^{+}, \Re\right)$, there exists a real constant satisfied by $\gamma_{1}$ :

$$
\left\|\varepsilon\left(\mathrm{u}, \dot{\mathrm{u}}, \hat{\mathrm{x}}_{\mathrm{a}}\right)-\varepsilon\left(\mathrm{u}, \dot{\mathrm{u}}, \mathrm{x}_{\mathrm{a}}\right)\right\| \leq \gamma_{1}\left\|\mathrm{x}_{\mathrm{a}}-\hat{\mathrm{x}}_{\mathrm{a}}\right\|
$$

Assumption 1. It refers to the global Lipchitz-type condition of function $\varepsilon$, although this condition seems restrictive, becomes much lower since $u$ and $u_{\mathrm{a}}$ are bounded, which is usually the case in physical situations.

Moreover, this boundedness can be found by introducing saturation in the argument of $h_{a}$. According to [29], if $u$ and $h_{a}$ belong to a compact set $\mathfrak{U}, \mathfrak{Y}$, then the global Lipchitz-type condition of function $\varepsilon$ can be replaced by local smoothness by using saturations.

Thus, a new interconnected system is constituted of $\Sigma^{\prime}:=\Sigma_{\mathrm{p}}+\Sigma_{\mathrm{a}}+\mathrm{x}_{\mathrm{u}}$ :

$$
\Sigma^{\prime}:\left\{\begin{array}{l}
\dot{x}=f(x)+g(x) x_{u} \\
\dot{x}_{u}=\varepsilon\left(u, u, x_{a}\right) \\
\dot{x}_{a}=f_{a}\left(x_{a}, u\right) \\
y=x \\
x\left(t_{0}\right)=x_{0} ; x_{a}\left(t_{0}\right)=x_{a} ; x_{u}=h_{a}\left(x_{a}, u\right)
\end{array}\right.
$$

where the input of the system is $\mathrm{u}$, the output is $\mathrm{y}$, and $\mathrm{x}_{\mathrm{u}}$ is an unmeasured state.

Let $\xi_{1}=\left[\begin{array}{ll}\xi_{11} & \xi_{12}\end{array}\right]=\left[\begin{array}{ll}x & x_{u}\end{array}\right], \xi_{2}=x_{a}$. Thus, the above system becomes

$$
\Sigma^{\prime}:\left\{\begin{array}{l}
\dot{\xi}_{1}=\overline{\mathrm{f}}_{1}\left(\xi_{1}, \xi_{2}, \mathrm{u}\right) \\
\dot{\xi}_{2}=\overline{\mathrm{f}}_{2}\left(\xi_{2}, \mathrm{u}\right) \\
\left(\begin{array}{c}
\mathrm{y}_{1} \\
\mathrm{y}_{2}
\end{array}\right)=\left(\begin{array}{c}
\mathrm{h}_{1}\left(\xi_{11}\right) \\
\mathrm{h}_{2}\left(\xi_{2}\right)
\end{array}\right)
\end{array}\right.
$$

where $\bar{f}_{1}\left(\xi_{1}, \xi_{2}, u\right):=\left(\begin{array}{c}f\left(\xi_{11}\right)+\mathrm{g}\left(\xi_{11}\right) \xi_{12} \\ \varepsilon\left(\mathrm{u}, \dot{\mathrm{u}}, \xi_{2}\right)\end{array}\right), \overline{\mathrm{f}}_{2}\left(\xi_{2}, \overline{\mathrm{u}}\right):=\mathrm{f}_{\mathrm{a}}\left(\xi_{2}, \mathrm{u}\right)$, and $\left(\begin{array}{c}\mathrm{h}_{1}\left(\xi_{11}\right) \\ \mathrm{h}_{2}\left(\xi_{2}\right)\end{array}\right):=\left(\begin{array}{c}\xi_{11} \\ \mathrm{~h}_{\mathrm{a}}\left(\mathrm{x}_{\mathrm{a}}, \mathrm{u}\right)\end{array}\right)$.

The above system can be divided into two subsystems:

$$
\Sigma_{\mathrm{O}_{\mathrm{i}}}:\left\{\begin{array}{l}
\dot{\xi}_{\mathrm{i}}=\overline{\mathrm{f}}_{\mathrm{i}}\left(\xi_{\mathrm{i}}, \xi_{\bar{i}}, \mathrm{u}\right) \\
\mathrm{y}_{\mathrm{i}}=\mathrm{h}_{\mathrm{i}}\left(\xi_{\mathrm{i}}\right)
\end{array}\right.
$$

where $\mathrm{i}=\{1,2\}$ and $\bar{i}$ denotes the complementary index of $\mathrm{i}(\mathrm{i} . \mathrm{e} .,\{\mathrm{i}, \bar{i}\}=\{1,2\})$. 


\subsubsection{State Estimator Design for the New Process Subsystem}

The following system can be viewed as a transformed form of the process subsystem described in Equation (1):

$$
\Sigma_{\mathrm{P}^{\prime}}:\left\{\begin{array}{l}
\dot{\xi}_{1}=\overline{\mathrm{f}}_{1}\left(\xi_{1}, \xi_{2}, \mathrm{u}\right) \\
\mathrm{y}_{1}=\xi_{11}
\end{array}\right.
$$

where $\bar{f}_{1}\left(\xi_{1}, \xi_{2}, \mathrm{u}\right):=\left(\begin{array}{l}\mathrm{f}\left(\xi_{11}\right)+\mathrm{g}\left(\xi_{11}\right) \xi_{12} \\ \varepsilon\left(\mathrm{u}, \dot{\mathrm{u}}, \xi_{2}\right)\end{array}\right)$.

The new process subsystem in Equation (9) can be expressed as follows:

$$
\Sigma_{\mathrm{P}^{\prime}}:\left\{\begin{array}{l}
\dot{\xi}_{1}=\mathrm{G}\left(\xi_{11}\right) \xi_{1}+\mathrm{F}\left(\xi_{11}\right)+\bar{\varepsilon}\left(\mathrm{u}, \dot{\mathrm{u}}, \xi_{2}\right) \\
\mathrm{y}_{1}=\mathrm{C} \xi_{1}
\end{array}\right.
$$

where $G\left(\xi_{11}\right)=\left(\begin{array}{cc}0 & \mathrm{~g}\left(\xi_{11}\right) \\ 0 & 0\end{array}\right), \mathrm{F}\left(\xi_{11}\right)=\left(\begin{array}{c}\mathrm{f}\left(\xi_{11}\right) \\ 0\end{array}\right), C\left(\begin{array}{cc}\mathrm{I}_{\mathrm{n}} & 0\end{array}\right), \bar{\varepsilon}\left(\mathrm{u}, \dot{\mathrm{u}}, \xi_{2}\right)=\left[\begin{array}{ll}0 & \varepsilon\left(\mathrm{u}, \dot{\mathrm{u}}, \xi_{2}\right)\end{array}\right]^{\mathrm{T}}$, and $\mathrm{I}_{\mathrm{n}}$ is the $\mathrm{n} \times \mathrm{n}$ identity matrix.

As demonstrated in [30], supposing that the following assumptions related to the boundedness of the states, signals, and functions are satisfied, an extended, high-gain observer for the system in Equation (10) can be formed.

Assumption 2. It states that there exist finite real numbers $\varrho$, $\tau$ with $0<\varrho \leq \tau$, and that $\varrho^{2} I_{n} \leq$ $F^{T}\left(\xi_{11}\right) F\left(\xi_{11}\right) \leq \tau^{2} I_{n}$.

Assumption 3. Is that $F\left(\xi_{11}\right)$ is a global Lipchitz, with respect to $\xi_{11}$, locally and uniformly with respect to $u$.

Assumption 4. It states that $g\left(\xi_{11}\right)$ is a global Lipchitz with respect to $\xi_{11}$.

Then, an extended, high-gain observer for the system in Equation (10) can be given as

$$
\Sigma_{\mathrm{PO}^{\prime}}:\left\{\begin{array}{l}
\dot{\hat{\varepsilon}}_{1}=\mathrm{G}\left(\hat{\varepsilon}_{11}\right) \hat{\xi}_{1}+\mathrm{F}\left(\hat{\varepsilon}_{11}\right)+\bar{\varepsilon}\left(\mathrm{u}, \dot{\mathrm{u}}, \hat{\varepsilon}_{2}\right)-\Lambda^{-1}\left(\hat{\varepsilon}_{1}\right) \mathrm{S}_{\theta}^{-1} \mathrm{C}^{\mathrm{T}}\left(\mathrm{C} \hat{\varepsilon}_{1}-\mathrm{y}_{1}\right) \\
\mathrm{y}_{1}=\mathrm{C} \hat{\varepsilon}_{1}
\end{array}\right.
$$

where $\mathrm{H}\left(\hat{\varepsilon}_{1}\right):=\Lambda^{-1}\left(\hat{\varepsilon}_{1}\right) \mathrm{S}_{\theta}^{-1} \mathrm{C}^{\mathrm{T}}$ is the gain function and $\Lambda\left(\hat{\varepsilon}_{1}\right):=\left[\begin{array}{cc}\mathrm{I} & 0 \\ 0 & \mathrm{~g}\left(\hat{\varepsilon}_{11}\right)\end{array}\right], \mathrm{S}_{\theta}$ is the unique symmetric positive definite matrix, satisfying the following algebraic Lyapunov equation:

$$
\theta \mathrm{S}_{\theta}+\mathrm{A}^{\mathrm{T}} \mathrm{S}_{\theta}+\mathrm{S}_{\theta} \mathrm{A}-\mathrm{C}^{\mathrm{T}} \mathrm{C}=0
$$

where $\mathrm{A}=\left[\begin{array}{ll}0 & \mathrm{I} \\ 0 & 0\end{array}\right], \theta>0$ is a parameter defined by Equation (12), and the solution is

$$
\mathrm{S}_{\theta}=\left[\begin{array}{cc}
\frac{1}{\theta} \mathrm{I} & -\frac{1}{\theta^{2}} \mathrm{I} \\
-\frac{1}{\theta^{2}} \mathrm{I} & \frac{2}{\theta^{3}} \mathrm{I}
\end{array}\right]
$$

Then, the gain of the estimator can be given by

$$
\mathrm{H}\left(\hat{\xi}_{1}\right)=\Lambda^{-1}\left(\hat{\xi}_{1}\right) \mathrm{S}_{\theta}^{-1} \mathrm{C}^{\mathrm{T}}=\left[\begin{array}{c}
2 \theta \mathrm{I} \\
\theta^{2} \mathrm{~g}^{-1}\left(\hat{\xi}_{11}\right)
\end{array}\right]
$$

The state estimation error is expressed as

$$
\mathrm{e}_{\mathrm{p}}(\mathrm{t})=\hat{\xi}_{1}(\mathrm{t})-\xi_{1}(\mathrm{t})
$$


Then, by subtracting the corresponding Equations (10) and (11), the following error dynamics can be obtained:

$$
\dot{e}_{\mathrm{p}}=\mathrm{G}\left(\hat{\varepsilon}_{11}\right) \hat{\varepsilon}_{1}+\mathrm{F}\left(\hat{\varepsilon}_{11}\right)+\bar{\varepsilon}\left(\mathrm{u}, \dot{\mathrm{u}}, \hat{\xi}_{2}\right)+\mathrm{H}\left(\hat{\xi}_{1}\right)\left(\mathrm{C} \hat{\xi}_{1}-\mathrm{y}\right)-\mathrm{G}\left(\xi_{11}\right) \xi_{1}-\mathrm{F}\left(\xi_{11}\right)-\bar{\varepsilon}\left(\mathbf{u}, \dot{\mathrm{u}}, \xi_{2}\right)
$$

Assumption 5. Is that for any $u \in \mathfrak{U}\left(t, e_{p}\right) \in \mathcal{A} \cdot \mathcal{C}\left(\Re^{+}, \Re\right)$, there exists a continuously differentiable function $V_{p}$, and the positive constants $\alpha_{1}, \beta_{1}, \gamma_{11}, \gamma_{12}$ satisfy the following:

$$
\left\{\begin{array}{l}
\text { (a) } \gamma_{11}\left\|e_{p}\right\|^{2} \leq V_{p}\left(t, e_{p}\right) \leq \gamma_{12}\left\|e_{p}\right\|^{2} \\
\text { (b) } \frac{\partial V_{p}}{\partial t}\left(t, e_{p}\right)+\frac{\partial V_{p}}{\partial e_{p}}\left(t, e_{p}\right) \dot{e}_{p} \leq-\alpha_{1} e_{p}^{2} \\
\text { (c) }\left\|\frac{\partial V_{p}}{\partial e_{p}}\left(t, e_{p}\right)\right\| \leq \beta_{1}\left\|e_{p}\right\|
\end{array}\right.
$$

Theorem 1. It states that if Assumption 1 and Assumption 5 are satisfied by properly choosing a relatively high-gain tuner parameter $\theta$ such that the following conditions are met: (1) if $\left\|\xi_{2}-\hat{\xi}_{2}\right\|$ converges to 0 , then make $\theta>\frac{\eta_{1}}{\alpha_{1}}$, and (2) if $\left\|\xi_{2}-\hat{\xi}_{2}\right\|$ is bounded by $\widetilde{e}_{p}$, then choose a value for $\theta$ such that $\left(\theta^{*} \alpha_{1}-\eta_{1}-\frac{\eta_{2}}{\theta^{*}}\right) \geq 0$.

Then, the system in Equation (11) becomes a converging observer for the system described in Equation (10), which is a transformed form of the process subsystem described in Equation (1).

The proof is given in Appendix A.

\subsubsection{State Estimator Design for the New Actuator Subsystem}

Equation (18) can be viewed as a transformed form of the actuator subsystem described in Equation (2):

$$
\Sigma_{\mathrm{a} \prime}:\left\{\begin{array}{l}
\dot{\xi}_{2}=\overline{\mathrm{f}}_{2}\left(\xi_{2}, \mathrm{u}\right) \\
\mathrm{y}_{2}=\mathrm{h}_{2}\left(\xi_{2}, \mathrm{u}\right)
\end{array}\right.
$$

where $\overline{\mathrm{f}}_{2}\left(\xi_{2}, \mathrm{u}\right):=\mathrm{f}_{\mathrm{a}}\left(\xi_{2}, \mathrm{u}\right)$.

A convergence observer can be designed for the system in Equation (18) as follows:

$$
\Sigma_{\mathrm{aO}^{\prime}}:\left\{\begin{array}{l}
\dot{\hat{\xi}}_{2}=\overline{\mathrm{f}}_{2}\left(\hat{\xi}_{2}, \mathrm{u}\right)+\mathrm{\kappa}_{2}\left(g_{2}, \hat{\xi}_{2}\right)\left(\mathrm{h}_{2}\left(\hat{\xi}_{2}\right)-\mathrm{y}_{2}\right) \\
\dot{g}_{2}=\Theta_{2}\left(\hat{\xi}_{2}, \mathrm{u}, q_{2}\right)
\end{array}\right.
$$

where $\kappa_{2}$ and $\Theta_{2}$ are smooth gain functions, with respect to their arguments, the state variable $\left(q_{2}, \hat{\xi}_{2}\right)$ belongs to $\left(\Re^{\mathrm{n}} \times \Theta_{2}\right)$, and $\Theta_{2}$ is a subset of $\Re^{\mathrm{n}}$, which is positively invariant by the second equation of (19).

The state estimation error is defined as

$$
\mathrm{e}_{\mathrm{a}}:=\hat{\xi}_{2}(\mathrm{t})-\xi_{2}(\mathrm{t})
$$

Then, by subtracting the corresponding Equations (18) and (19), we get the following error dynamics:

$$
\dot{\mathrm{e}}_{\mathrm{a}}\left(\mathrm{t}, \mathrm{e}_{\mathrm{a}}\right)=\overline{\mathrm{f}}_{2}\left(\xi_{2}, \mathrm{u}\right)-\overline{\mathrm{f}}_{2}\left(\hat{\xi}_{2}, \mathrm{u}\right)-\mathrm{\kappa}_{2}\left(g_{2}, \hat{\xi}_{2}\right)\left(\mathrm{h}_{2}\left(\hat{\xi}_{2}\right)-\mathrm{y}_{2}\right)
$$

where $\mathrm{K}_{2}\left(\mathrm{u}, \hat{\xi}_{2}, \mathrm{y}_{2}\right):=\mathrm{\kappa}_{2}\left(\mathrm{q}_{2}, \hat{\xi}_{2}\right)\left(\mathrm{h}_{2}\left(\hat{\xi}_{2}\right)-\mathrm{y}_{2}\right)$.

In order to formulate a solution to the convergence of the above observer, we need to follow Assumption 6, with respect to the error Lyapunov function introduced in [26]. This error Lyapunov function shows the equivalence of the existence of an error Lyapunov function and the existence of a converging observer. 
Assumption 6. Is that for any $u \in \mathfrak{U}\left(t, e_{\mathrm{a}}\right) \in \mathcal{A} \cdot \mathcal{C}\left(\Re^{+}, \Re\right)$, there exists a continuously differentiable function $V_{\mathrm{a}}$ and positive constants $\alpha_{2}, \beta_{2}, \gamma_{21}, \gamma_{22}$ to satisfy

$$
\left\{\begin{array}{l}
\text { (a) } \gamma_{21}\left\|\mathrm{e}_{\mathrm{a}}\right\|^{2} \leq \mathrm{V}_{\mathrm{a}}\left(\mathrm{t}, \mathrm{e}_{\mathrm{a}}\right) \leq \gamma_{22}\left\|\mathrm{e}_{\mathrm{a}}\right\|^{2} \\
\text { (b) } \frac{\partial \mathrm{V}_{\mathrm{a}}}{\partial \mathrm{t}}\left(\mathrm{t}, \mathrm{e}_{a}\right)+\frac{\partial \mathrm{V}_{a}}{\partial \mathrm{e}_{a}}\left(\mathrm{t}, \mathrm{e}_{a}\right) \dot{\mathrm{e}}_{a} \leq-\alpha_{2}\left\|\mathrm{e}_{a}\right\|^{2} \\
\text { (c) }\left\|\frac{\partial \mathrm{V}_{\mathrm{a}}}{\partial \mathrm{e}_{a}}\left(\mathrm{t}, \mathrm{e}_{a}\right)\right\| \leq \beta_{2}\left\|\mathrm{e}_{a}\right\|
\end{array} .\right.
$$

The observer defined by Equation (19) is a converging observer if Assumption 6 is satisfied. However, the observer in Equation (19) can only be realized when the output $y_{2}$ is measurable, which is not the case. Due to this, $\mathrm{y}_{2}$ in our design represents the output of the actuator subsystem. It is assumed to be unmeasured and, therefore, $\mathrm{y}_{2}$ must be replaced by an estimate $\widetilde{\mathrm{y}}_{2}$ using the available measurements.

Fortunately, that estimation of $\widetilde{y}_{2}$ is available in the process subsystem observer in Equation (11). By substituting $u_{a}$ for $\widetilde{y}_{2}$, we can now implement the observer in Equation (19) for an actuator subsystem as

$$
\Sigma_{\mathrm{aO}^{\prime \prime}}:\left\{\begin{array}{l}
\dot{\hat{\xi}}_{2}=\overline{\mathrm{f}}_{2}\left(\hat{\xi}_{2}, \mathrm{u}\right)+\mathrm{\kappa}_{2}\left(\mathrm{q}_{2}, \hat{\xi}_{2}\right)\left(\mathrm{h}_{2}\left(\hat{\xi}_{2}\right)-\widetilde{\mathrm{y}}_{2}\right) \\
\dot{q}_{\mathrm{a}}=\Theta_{2}\left(\hat{\xi}_{2}, \mathrm{u}, g_{2}\right)
\end{array}\right.
$$

where $\mathrm{K}_{2}\left(\mathrm{u}, \hat{\xi}_{2}, \widetilde{\mathrm{y}}_{2}\right):=\kappa_{2}\left(q_{2}, \hat{\xi}_{2}\right)\left(\mathrm{h}_{2}\left(\hat{\xi}_{2}\right)-\widetilde{\mathrm{y}}_{2}\right)$.

The estimation error is produced again by subtracting the corresponding equation in Equations (18) and (23), and the new error dynamics are achieved as follows:

$$
\begin{aligned}
\dot{\mathrm{e}}_{\mathrm{a}}\left(\mathrm{t}, \widetilde{\mathrm{e}}_{\mathrm{a}}\right) & =\overline{\mathrm{f}}_{2}\left(\xi_{2}, \mathrm{u}\right)-\overline{\mathrm{f}}_{2}\left(\hat{\xi}_{2}, \mathrm{u}\right)-\mathrm{K}_{2}\left(\mathrm{u}, \hat{\xi}_{2}, \widetilde{\mathrm{y}}_{2}\right) \\
& =\overline{\mathrm{f}}_{2}\left(\xi_{2}, \mathrm{u}\right)-\overline{\mathrm{f}}_{2}\left(\hat{\xi}_{2}, \mathrm{u}\right)-\mathrm{K}_{2}\left(\mathrm{u}, \hat{\xi}_{2}, \mathrm{y}_{2}\right)+\mathrm{K}_{2}\left(\mathrm{u}, \hat{\xi}_{2}, \mathrm{y}_{2}\right)-\mathrm{K}_{2}\left(\mathrm{u}, \hat{\xi}_{2}, \widetilde{\mathrm{y}}_{2}\right) \\
& =\dot{\mathrm{e}}_{\mathrm{a}}\left(\mathrm{t}, \mathrm{e}_{\mathrm{a}}\right)+\mathrm{K}_{2}\left(\mathrm{u}, \hat{\xi}_{2}, \mathrm{y}_{2}\right)-\mathrm{K}_{2}\left(\mathrm{u}, \hat{\xi}_{2}, \widetilde{\mathrm{y}}_{2}\right)
\end{aligned}
$$

In order to ensure the stability of the error dynamics in Equation (24), an assumption is required with respect to the sensitivity of $\mathrm{K}_{2}\left(\mathrm{u}, \hat{\varepsilon}_{2}, \mathrm{y}_{2}\right)$, with changes of $\mathrm{y}_{2}$.

Assumption 7. It provides a sufficient condition for achieving this purpose, stating that for any $u \in \mathfrak{U},\left(t, \hat{\xi}_{2}, \widetilde{y}_{2}\right) \in \mathcal{A} \cdot \mathcal{C}\left(\Re^{+}, \Re\right)$, there exists a real constant $\gamma_{2}$ to satisfy

$$
\left\|\mathrm{K}_{2}\left(\mathrm{u}, \hat{\xi}_{2}, \widetilde{\mathrm{y}}_{2}\right)-\mathrm{K}_{2}\left(\mathrm{u}, \hat{\xi}_{2}, \mathrm{y}_{2}\right)\right\| \leq \gamma_{2}\left\|\mathrm{y}_{2}-\widetilde{\mathrm{y}}_{2}\right\|
$$

Similar to Assumption 1, Assumption 7 implies a global Lipchitz-type condition on function $\mathrm{K}_{2}$ such that, in a physical problem, $\mathrm{u}, \mathrm{y}_{2}$ are bounded. Therefore, it can also be replaced by a local smoothness condition.

In addition to asking that the state estimation error $\mathrm{e}_{\mathrm{a}}$ converge to 0 in the absence of disturbances, we want it to still converge to 0 if a disturbance is present, but converge to 0 and remain bounded if the disturbance is bounded. Therefore, Assumption 7 implies that the definition of $\dot{\widetilde{\mathrm{e}}}_{\mathrm{a}}\left(\mathrm{t}, \widetilde{\mathrm{e}}_{\mathrm{a}}\right)$ in $(24)$ is not affected.

In particular, since output $\widetilde{y}_{2}$, used in the observer in Equation (23), is in fact a virtual measurement which is estimated by the output of the process subsystem, an estimation error becomes unavoidable. This estimation error can be viewed as a bounded disturbance to the real output of the actuator subsystem $\mathrm{y}_{2}$. Therefore, the basic problem addressed in this work is the design of nonlinear observers that possesses robustness to the disturbance affecting the real output.

Theorem 2. It says that if Assumptions 6 and 7 are satisfied, then the observer described in Equation (23) is a converging observer for the actuator subsystem described in Equation (18).

The proof is given in Appendix B. 


\subsubsection{Interconnected Observer}

The interconnected observer for the studied interconnected system by the system in Equations (11) and (23) is constituted as follows:

$$
\Sigma_{\mathrm{O}}^{\prime}:\left\{\begin{array}{l}
\dot{\hat{\xi}}_{1}=\mathrm{G}\left(\hat{\xi}_{11}\right) \hat{\xi}_{1}+\mathrm{F}\left(\hat{\xi}_{11}\right)+\bar{\varepsilon}\left(\mathrm{u}, \dot{\mathrm{u}}_{1}, \hat{\xi}_{2}\right)-\Lambda^{-1}\left(\hat{\xi}_{1}\right) \mathrm{S}_{\theta}^{-1} \mathrm{C}^{\mathrm{T}}\left(\mathrm{C} \hat{\xi}_{1}-\mathrm{y}_{1}\right) \\
\dot{\hat{\varepsilon}}_{2}=\overline{\mathrm{f}}_{2}\left(\hat{\xi}_{2}, \mathrm{u}\right)+\mathrm{k}_{2}\left(\mathrm{q}_{2}, \hat{\varepsilon}_{2}\right)\left(\mathrm{h}_{2}\left(\hat{\varepsilon}_{2}\right)-\hat{\xi}_{12}\right)
\end{array}\right.
$$

where the virtual measurement $\widetilde{y}_{2}$ in Equation (23) is replaced by the estimation $\hat{\xi}_{12}$. The observer estimation errors satisfy the following equation:

$$
\mathrm{e}_{\mathrm{p}}(\mathrm{t})=\hat{\xi}_{1}(\mathrm{t})-\xi_{1}(\mathrm{t}), \quad \widetilde{\mathrm{e}}_{\mathrm{a}}(\mathrm{t})=\hat{\xi}_{2}(\mathrm{t})-\xi_{2}(\mathrm{t})
$$

\subsection{Interconnected Observer Analysis}

The observer in Equation (26) has been designed so that the dynamics of the corresponding error system in Equation (27) are governed as follows:

$$
\left\{\begin{array}{l}
\dot{e}_{\mathrm{p}}\left(\mathrm{t}, \mathrm{e}_{\mathrm{p}}\right)=\mathrm{G}\left(\hat{\xi}_{11}\right) \hat{\xi}_{1}+\mathrm{F}\left(\hat{\xi}_{11}\right)+\bar{\varepsilon}\left(\mathrm{u}, \dot{\mathrm{u}}_{1}, \hat{\xi}_{2}\right)+\mathrm{H}\left(\hat{\varepsilon}_{1}\right)\left(\mathrm{C} \hat{\varepsilon}_{1}-\mathrm{y}\right)-\mathrm{G}\left(\xi_{11}\right) \xi_{1}-\mathrm{F}\left(\xi_{11}\right)-\bar{\varepsilon}\left(\mathrm{u}, \dot{\mathrm{u}}, \xi_{2}\right) \\
\dot{\mathrm{e}}_{\mathrm{a}}\left(\mathrm{t}, \widetilde{\mathrm{e}}_{\mathrm{a}}\right)=\dot{\mathrm{e}}_{\mathrm{a}}\left(\mathrm{t}, \mathrm{e}_{\mathrm{a}}\right)+\mathrm{K}_{2}\left(\mathrm{u}, \hat{\xi}_{2}, \mathrm{~h}_{2}\left(\hat{\xi}_{2}\right)\right)-\mathrm{K}_{2}\left(\mathrm{u}, \hat{\xi}_{2}, \hat{\xi}_{12}\right)
\end{array}\right.
$$

To analyze the system in Equation (28), our purpose is to study the stability of the error dynamics.

Theorem 3. If Assumptions 1-7 are satisfied, then a relatively high value of $\theta$ can be chosen such that $1-\frac{1}{2 \sqrt{\alpha_{2}\left(\theta-\eta_{1}\right)}}\left(\eta_{3}+\frac{\eta_{2}}{\theta}\right)$, and the error dynamics governed in Equation (28) are convergent.

Proof. The objective is to analyze the stability of the error dynamics. To achieve this purpose, by using $\mathrm{V}_{\mathrm{a}}$ and $\mathrm{V}_{\mathrm{p}}$, defined in the proof of Theorems 1 and 2, the following Lyapunov function candidate is constructed:

$$
\mathrm{V}\left(\mathrm{t}, \widetilde{\mathrm{e}}_{\mathrm{p}}, \widetilde{\mathrm{e}}_{\mathrm{a}}\right)=\mathrm{V}_{\mathrm{p}}\left(\mathrm{t}, \widetilde{\mathrm{e}}_{\mathrm{p}}\right)+\mathrm{V}_{\mathrm{a}}\left(\mathrm{t}, \widetilde{\mathrm{e}}_{\mathrm{a}}\right)
$$

Then, the time derivation of $\mathrm{V}\left(\mathrm{t}, \widetilde{\mathrm{e}}_{\mathrm{p}}, \widetilde{\mathrm{e}}_{\mathrm{a}}\right)$ yields

$$
\dot{\mathrm{V}}\left(\mathrm{t}, \widetilde{\mathrm{e}}_{\mathrm{p}}, \widetilde{\mathrm{e}}_{\mathrm{a}}\right)=\underbrace{\frac{\partial V_{\mathrm{p}}}{\partial \mathrm{t}}\left(\mathrm{t}, \widetilde{\mathrm{e}}_{\mathrm{p}}\right)+\frac{\partial \mathrm{V}_{\mathrm{p}}}{\partial \mathrm{e}_{\mathrm{p}}}\left(\mathrm{t}, \widetilde{\mathrm{e}}_{\mathrm{p}}\right) \dot{\tilde{\mathrm{e}}}_{\mathrm{p}}\left(\mathrm{t}, \widetilde{\mathrm{e}}_{\mathrm{p}}\right)}_{\text {term } 1}+\underbrace{\frac{\partial \mathrm{V}_{\mathrm{a}}}{\partial \mathrm{t}}\left(\mathrm{t}, \widetilde{\mathrm{e}}_{\mathrm{a}}\right)+\frac{\partial \mathrm{V}_{\mathrm{a}}}{\partial \mathrm{e}_{\mathrm{a}}}\left(\mathrm{t}, \mathrm{e}_{\mathrm{a}}\right) \dot{\mathrm{e}}_{\mathrm{a}}\left(\mathrm{t}, \mathrm{e}_{\mathrm{a}}\right)+\frac{\partial \mathrm{V}_{\mathrm{a}}}{\partial \mathrm{e}_{\mathrm{a}}}\left(\mathrm{t}, \mathrm{e}_{\mathrm{a}}\right)\left(\mathrm{K}\left(\mathrm{u}, \hat{\xi}_{2}, \mathrm{y}_{2}\right)-\mathrm{K}\left(\mathrm{u}, \hat{\xi}_{2}, \hat{\xi}_{12}\right)\right)}_{\text {term2 }}
$$

Let us analyze the different terms on the right side of Equation (30), starting with term 1 and using results in the proof of Theorem 1:

$$
\begin{aligned}
\dot{\mathrm{V}}_{\mathrm{p}}\left(\mathrm{t}, \widetilde{\mathrm{e}}_{\mathrm{p}}\right)= & \frac{\partial \mathrm{V}_{\mathrm{p}}}{\partial \mathrm{t}}\left(\mathrm{t}, \widetilde{\mathrm{e}}_{\mathrm{p}}\right)+\frac{\partial \mathrm{V}_{\mathrm{p}}}{\partial \mathrm{e}_{\mathrm{p}}}\left(\mathrm{t}, \widetilde{\mathrm{e}}_{\mathrm{p}}\right) \dot{\tilde{\mathrm{e}}}_{\mathrm{p}}\left(\mathrm{t}, \widetilde{\mathrm{e}}_{\mathrm{p}}\right) \\
& \leq\left(-\theta+\eta_{1}\right) \mathrm{V}_{\mathrm{p}}+\frac{\eta_{2}}{\theta} \sqrt{\mathrm{V}_{\mathrm{p}}}\left\|\xi_{2}-\hat{\xi}_{2}\right\|
\end{aligned}
$$

In turn, by using results in the proof of Theorem 2, then term 2 on the right side of Equation (30) develops as follows:

$$
\begin{aligned}
& \dot{\mathrm{V}}_{\mathrm{a}}\left(\widetilde{\mathrm{e}}_{\mathrm{a}}\right)=\frac{\partial \mathrm{V}_{\mathrm{a}}}{\partial \mathrm{t}}\left(\mathrm{t}, \widetilde{\mathrm{e}}_{\mathrm{a}}\right)+\frac{\partial \mathrm{V}_{\mathrm{a}}}{\partial \mathrm{e}_{\mathrm{a}}}\left(\mathrm{t}, \mathrm{e}_{\mathrm{a}}\right) \dot{\mathrm{e}}_{\mathrm{a}}\left(\mathrm{t}, \mathrm{e}_{\mathrm{a}}\right)+\frac{\partial \mathrm{V}_{\mathrm{a}}}{\partial \mathrm{e}_{\mathrm{a}}}\left(\mathrm{t}, \mathrm{e}_{\mathrm{a}}\right)\left(\mathrm{K}_{2}\left(\mathrm{u}, \hat{\varepsilon}_{2}, \mathrm{y}_{2}\right)-\mathrm{K}_{2}\left(\mathrm{u}, \hat{\varepsilon}_{2}, \hat{\xi}_{12}\right)\right) \\
& \leq-\alpha_{2} V_{\mathrm{a}}+\eta_{3} \sqrt{\mathrm{V}_{\mathrm{a}}}\left\|\xi_{12}-\hat{\xi}_{12}\right\|
\end{aligned}
$$

Then, the overall inequality yields

$$
\dot{\mathrm{V}}\left(\mathrm{t}, \widetilde{\mathrm{e}}_{\mathrm{p}}, \widetilde{\mathrm{e}}_{\mathrm{a}}\right) \leq-\alpha_{2} \mathrm{~V}_{\mathrm{a}}+\eta_{3} \sqrt{\mathrm{V}_{\mathrm{p}}} \sqrt{\mathrm{V}_{\mathrm{a}}}+\left(-\theta+\eta_{1}\right) \mathrm{V}_{\mathrm{p}}+\frac{\eta_{2}}{\theta} \sqrt{\mathrm{V}_{\mathrm{p}}} \sqrt{\mathrm{V}_{\mathrm{a}}}
$$

Now, set $\mathrm{V}_{\mathrm{a}}^{*}=\alpha_{2} \mathrm{~V}_{\mathrm{a}}, \mathrm{V}_{\mathrm{p}}^{*}=\left(\theta-\eta_{1}\right) \mathrm{V}_{\mathrm{p}}$, and $\mathrm{V}^{*}=\mathrm{V}_{\mathrm{a}}^{*}+\mathrm{V}_{\mathrm{p}}^{*}$. 
Let us assume that

$$
\varsigma=\min \left\{\alpha_{2},\left(\theta-\eta_{1}\right)\right\}
$$

In this case,

$$
\mathrm{V}^{*} \leq 2 \varsigma V
$$

It should also be noted that

$$
\begin{aligned}
\mathrm{V}_{\mathrm{p}}^{*}+\mathrm{V}_{\mathrm{a}}^{*} & \geq 2 \sqrt{\mathrm{V}_{\mathrm{p}}^{*}} \sqrt{\mathrm{V}_{\mathrm{a}}^{*}} \\
& =2 \sqrt{\alpha_{2}\left(\theta-\eta_{1}\right)} \sqrt{\mathrm{V}_{\mathrm{p}}} \sqrt{\mathrm{V}_{\mathrm{a}}}
\end{aligned}
$$

Thus,

$$
\sqrt{\mathrm{V}_{\mathrm{p}}} \sqrt{\mathrm{V}_{\mathrm{a}}} \leq \frac{1}{2 \sqrt{\alpha_{2}\left(\theta-\eta_{1}\right)}} \mathrm{V}^{*}
$$

It is easy to get that inequality in Equation (33) to yield the following:

$$
\begin{aligned}
\dot{\mathrm{V}}\left(\widetilde{\mathrm{e}}_{\mathrm{p}}, \widetilde{\mathrm{e}}_{\mathrm{a}}\right) & \leq-\mathrm{V}^{*}+\frac{1}{2 \sqrt{\alpha_{2}\left(\theta-\eta_{1}\right)}}\left(\eta_{3}+\frac{\eta_{2}}{\theta}\right) \mathrm{V}^{*} \\
& \leq-\left(1-\frac{1}{2 \sqrt{\alpha_{2}\left(\theta-\eta_{1}\right)}}\left(\eta_{3}+\frac{\eta_{2}}{\theta}\right)\right) \mathrm{V}^{*} \\
& \leq-2 \varsigma\left(1-\frac{1}{2 \sqrt{\alpha_{2}\left(\theta-\eta_{1}\right)}}\left(\eta_{3}+\frac{\eta_{2}}{\theta}\right)\right) \mathrm{V}
\end{aligned}
$$

Now, it suffices to choose a value of $\theta$ such that $\left(1-\frac{1}{2 \sqrt{\alpha_{2}\left(\theta-\eta_{1}\right)}}\left(\eta_{3}+\frac{\eta_{2}}{\theta}\right)\right) \geq 0$.

This ends the proof.

\section{Simulations}

Numerical simulations were performed to validate that the interconnected observer given by Equation (26) can be implemented for monitoring the performance of an interconnected system. A case study was developed on an intensified heat exchanger (IHEX). The pilot consisted of three process plates sandwiched between five utility plates. Two pneumatic control valves were used to control the utility and process fluid. More relative information could be found in [17]. Moreover, the outlet fluid flow rates of the control valves were assumed to be unmeasured to ensure a realistic simulation. Therefore, during the course of the simulation work, the proposed observers were designed for estimating unmeasured inlet fluid flows and monitoring the performance of the IHEX.

\subsection{System Modelling}

\subsubsection{Actuator Subsystem Modelling}

The pneumatic control valve is used to act as an actuator in this system. By applying Bernoulli's continuous flow law of incompressible fluids, we have

$$
F=C_{V} f(X) \sqrt{\frac{\Delta P}{s g}}
$$

where $\mathrm{F}$ is the flow rate $\left(\mathrm{m}^{3} \mathrm{~s}^{-1}\right), \Delta \mathrm{P}$ is the fluid pressure drop across the valve $(\mathrm{Pa}), \mathrm{sg}$ is the specific gravity of the fluid and equals 1 for pure water, $X$ is the valve opening percentage, $C_{V}$ is the valve coefficient, and $f(X)$ is the flow characteristic which is defined as the relationship between the valve capacity and fluid traveling through the valve. In [3], a pneumatic control valve had a dynamic model as follows:

$$
\mathrm{m} \frac{\mathrm{d}^{2} \mathrm{X}}{\mathrm{dt}}+\mu \frac{\mathrm{dX}}{\mathrm{dt}}+\mathrm{kX}=\mathrm{p}_{\mathrm{c}} \mathrm{A}_{a}
$$




$$
\frac{\mathrm{dp}_{\mathrm{c}}}{\mathrm{dt}}=\left(\mathrm{p}_{\mathrm{c}}+\mathrm{p}_{\mathrm{a}}\right)\left(C V P-\frac{\mathrm{A}_{a}}{V_{0}+\mathrm{A}_{a} \mathrm{X}} \frac{\mathrm{dX}}{\mathrm{dt}}\right)
$$

where $\mathrm{A}_{a}$ is the diaphragm area on which the pneumatic pressure acts, $\mathrm{p}_{\mathrm{c}}$ is the pneumatic pressure, $\mathrm{m}$ is the mass of the control valve stem, $\mu$ is the friction of the valve stem, $\mathrm{k}$ is the spring compliance, $\mathrm{X}$ is the stem displacement or percentage opening of the valve, $C V P$ is the command pressure, and $\mathrm{p}_{\mathrm{a}}$ is the air pressure. The following definitions also apply:

$$
\begin{aligned}
& \mathrm{x}_{\mathrm{a}}^{\mathrm{T}}=\left[\begin{array}{lllll}
\mathrm{x}_{\mathrm{a} 1} & \mathrm{x}_{\mathrm{a} 2} & \mathrm{x}_{\mathrm{a} 3} & \mathrm{x}_{\mathrm{a} 4} \mathrm{x}_{\mathrm{a} 5} & \mathrm{x}_{\mathrm{a} 6}
\end{array}\right]=\left[\begin{array}{llll}
\mathrm{x}_{1} & \frac{\mathrm{dx} 1}{\mathrm{dt}} \mathrm{p}_{\mathrm{c} 1} & \mathrm{x}_{2} & \frac{\mathrm{dx}}{\mathrm{dt}} \mathrm{p}_{\mathrm{c} 2}
\end{array}\right] \\
& \mathrm{u}^{\mathrm{T}}=\left[\begin{array}{ll}
\mathrm{u}_{1} & \mathrm{u}_{2}
\end{array}\right]=\left[\begin{array}{ll}
C V P_{1} & C V P_{2}
\end{array}\right], \mathrm{u}_{\mathrm{a}}^{\mathrm{T}}=\left[\begin{array}{ll}
\mathrm{F}_{1} & \mathrm{~F}_{2}
\end{array}\right]=\left[\begin{array}{ll}
\mathrm{C}_{\mathrm{v}} \sqrt{\frac{\Delta \mathrm{P}_{1}}{\mathrm{sg}}} \mathrm{X}_{1} & \mathrm{C}_{\mathrm{v}} \sqrt{\frac{\Delta \mathrm{P}_{2}}{\mathrm{sg}}} \mathrm{X}_{2}
\end{array}\right] \\
& \mathrm{C}=\left[\begin{array}{lllll}
\mathrm{c}_{1} & \mathrm{c}_{2} & \mathrm{c}_{3} & \mathrm{c}_{4} \mathrm{C}_{5} & \mathrm{c}_{6}
\end{array}\right]=\left[\begin{array}{llllll}
\mathrm{C}_{\mathrm{v}} \sqrt{\frac{\Delta \mathrm{P}_{1}}{\mathrm{sg}}} & 0 & 0 & \mathrm{C}_{\mathrm{v}} \sqrt{\frac{\Delta \mathrm{P}_{2}}{\mathrm{sg}}} & 0 & 0
\end{array}\right]
\end{aligned}
$$

where $\mathrm{p}_{\mathrm{c} 1}, \mathrm{p}_{\mathrm{c} 2}, \mathrm{X}_{1}, \mathrm{X}_{2}, C V P_{1}, C V P_{2}, \Delta \mathrm{P}_{1}$, and $\Delta \mathrm{P}_{2}$ correspond to $\mathrm{p}_{\mathrm{c}^{\prime}}, \mathrm{X}, C V P$, and $\Delta \mathrm{P}$ in Equations (36)-(38), respectively, and subscripts one and two represent two different control valves. The actuator subsystem is then described as

$$
\left\{\begin{array}{l}
\dot{x}_{\mathrm{a} 1}=\mathrm{x}_{\mathrm{a} 2} \\
\dot{\mathrm{x}}_{\mathrm{a} 2}=-\frac{\mathrm{k}_{1}}{\mathrm{~m}} \mathrm{x}_{\mathrm{a} 1}-\frac{\mu_{1}}{\mathrm{~m}} \mathrm{x}_{\mathrm{a} 2}+\frac{\mathrm{A}_{\mathrm{a}}}{\mathrm{m}} \mathrm{x}_{\mathrm{a} 3} \\
\dot{\mathrm{x}}_{\mathrm{a} 3}=\mathrm{x}_{\mathrm{a} 3} \mathrm{u}_{1}-\frac{A_{\mathrm{a}}}{V_{0}+A_{\mathrm{a}} \mathrm{x}_{\mathrm{a}}} \mathrm{x}_{\mathrm{a} 3} \mathrm{x}_{\mathrm{a} 2}+\mathrm{p}_{\mathrm{a}} \mathrm{u}_{1}-\frac{\mathrm{A}_{\mathrm{a}} \mathrm{p}_{\mathrm{a}}}{V_{0}+\mathrm{A}_{\mathrm{a}} \mathrm{x}_{\mathrm{a}}} \mathrm{x}_{\mathrm{a} 2} \\
\dot{\mathrm{x}}_{\mathrm{a} 4}=\mathrm{x}_{\mathrm{a} 5} \\
\dot{\mathrm{x}}_{\mathrm{a} 5}=-\frac{\mathrm{k}_{2}}{\mathrm{~m}} \mathrm{x}_{\mathrm{a} 4}-\frac{\mu_{2}}{\mathrm{~m}} \mathrm{x}_{\mathrm{a} 5}+\frac{\mathrm{A}_{\mathrm{a}}}{\mathrm{m}} \mathrm{x}_{\mathrm{a} 6} \\
\dot{\mathrm{x}}_{\mathrm{a} 6}=\mathrm{x}_{\mathrm{a} 6} \mathrm{u}_{2}-\frac{A_{\mathrm{a}}}{V_{0}+\mathrm{A}_{\mathrm{a}} \mathrm{x}_{\mathrm{a}}} \mathrm{x}_{\mathrm{a} 5} \mathrm{x}_{\mathrm{a}}+\mathrm{p}_{\mathrm{a}} \mathrm{u}_{2}-\frac{\mathrm{A}_{\mathrm{a}} \mathrm{p}_{\mathrm{a}}}{V_{0}+\mathrm{A}_{\mathrm{a}} \mathrm{x}_{\mathrm{a} 4}} \mathrm{x}_{\mathrm{a} 5} \\
y=C x_{\mathrm{a}}
\end{array}\right.
$$

\subsubsection{Process Subsystem Modelling}

The IHEX can be modeled based on the mass and energy balances, which describe the evolution of characteristic values such as temperature, mass, composition, and pressure. Considering the heat exchanger system taken from [17], the dynamic equation governing the heat balance of the fluids is given by

$$
\begin{aligned}
& \dot{\mathrm{T}}_{\mathrm{p}}=\frac{\mathrm{UA}}{\rho_{\mathrm{p}} \mathrm{c}_{\mathrm{pp}} \mathrm{V}_{\mathrm{p}}}\left(\mathrm{T}_{\mathrm{u}}-\mathrm{T}_{\mathrm{p}}\right)+\frac{1}{\mathrm{~V}_{\mathrm{p}}}\left(\mathrm{T}_{\mathrm{pi}}-\mathrm{T}_{\mathrm{p}}\right) \mathrm{F}_{\mathrm{p}} \\
& \dot{\mathrm{T}}_{\mathrm{u}}=\frac{\mathrm{UA}}{\rho_{\mathrm{u}} \mathrm{c}_{\mathrm{pu}} \mathrm{V}_{\mathrm{u}}}\left(\mathrm{T}_{\mathrm{p}}-\mathrm{T}_{\mathrm{u}}\right)+\frac{1}{\mathrm{~V}_{\mathrm{u}}}\left(\mathrm{T}_{\mathrm{ui}}-\mathrm{T}_{\mathrm{u}}\right) \mathrm{F}_{\mathrm{u}}
\end{aligned}
$$

where $\rho_{\mathrm{p}}, \rho_{\mathrm{u}}$ are the densities of the fluids (in $\left.\mathrm{kg} \cdot \mathrm{m}^{-3}\right), \mathrm{V}_{\mathrm{p}}, \mathrm{V}_{\mathrm{u}}$ are the volumes of the fluids (in $\mathrm{m}^{3}$ ), $\mathrm{C}_{\mathrm{pp}}, \mathrm{c}_{\mathrm{pu}}$ are the specific heats of the fluids (in $\mathrm{J} \cdot \mathrm{kg}^{-1} \cdot \mathrm{K}^{-1}$ ), $\mathrm{U}$ is the overall heat transfer coefficient (in $\mathrm{J} \cdot \mathrm{m}^{-2} \cdot \mathrm{K}^{-1} \cdot \mathrm{s}^{-1}$ ), A is the reaction area (in $\mathrm{m}^{2}$ ), $\mathrm{F}_{\mathrm{p}}, \mathrm{F}_{\mathrm{u}}$ are the mass flow rates of the fluids (in $\mathrm{kg} \cdot \mathrm{s}^{-1}$ ), and $\mathrm{T}_{\mathrm{pi}}, \mathrm{T}_{\mathrm{ui}}$ are the inlet temperatures of the fluids.

If the state vector is defined as $x^{T}=\left[\mathrm{x}_{1}, \mathrm{x}_{2}\right]^{\mathrm{T}}=\left[\mathrm{T}_{\mathrm{p}}, \mathrm{T}_{\mathrm{u}}\right]^{\mathrm{T}}$, the control input as $\mathrm{u}_{\mathrm{a}}^{\mathrm{T}}=\left[\mathrm{u}_{\mathrm{a} 1}, \mathrm{u}_{\mathrm{a} 2}\right]^{\mathrm{T}}=\left[\mathrm{F}_{\mathrm{p}}, \mathrm{F}_{\mathrm{u}}\right]^{\mathrm{T}}$, and the output vector as $\mathrm{y}^{\mathrm{T}}=\left[\mathrm{y}_{1}, \mathrm{y}_{2}\right]^{\mathrm{T}}=\left[\mathrm{T}_{\mathrm{p}}, \mathrm{T}_{\mathrm{u}}\right]^{\mathrm{T}}$, then the above two equations can be rewritten as

$$
\left\{\begin{array}{l}
\dot{x}=f(x)+\sum_{i=1}^{2} g_{i}(x) u_{a} \\
y=h\left(x, u_{a}\right)
\end{array}\right.
$$

where $f(x)=\left(\begin{array}{c}f_{1}(x) \\ f_{2}(x)\end{array}\right)=\left(\begin{array}{c}\frac{h_{p} A}{\rho_{p} C_{p_{p}} V_{p}}\left(T_{p}-T_{u}\right) \\ \frac{h_{u} A}{\rho_{u} C_{p_{u}} V_{u}}\left(T_{u}-T_{p}\right)\end{array}\right), g(x)=\left(g_{1}, g_{2}\right)=\left(\begin{array}{cc}\frac{\left(T_{p i}-T_{p}\right)}{V_{p}} & 0 \\ 0 & \frac{\left(T_{u i}-T_{u}\right)}{V_{u}}\end{array}\right)$, and $\mathrm{y}_{1}=\mathrm{x}_{1}, \mathrm{y}_{2}=\mathrm{x}_{2}$. 
By using Equation (34), a function for the derivatives for $\mathrm{u}_{\mathrm{a}}$ is obtained:

$$
\begin{aligned}
& \dot{\mathrm{u}}_{\mathrm{a}}=\varepsilon\left(\mathrm{u}, \dot{\mathrm{u}}, \mathrm{x}_{\mathrm{a}}\right)=\frac{\partial \mathrm{h}_{\mathrm{a}}}{\partial \mathrm{u}}\left(\mathrm{u}, \mathrm{x}_{\mathrm{a}}\right) \dot{\mathrm{u}}+\frac{\partial \mathrm{h}_{\mathrm{a}}}{\partial \mathrm{x}_{\mathrm{a}}}\left(\mathrm{u}, \mathrm{x}_{\mathrm{a}}\right) \mathrm{f}_{\mathrm{a}}\left(\mathrm{u}, \mathrm{x}_{\mathrm{a}}\right)
\end{aligned}
$$

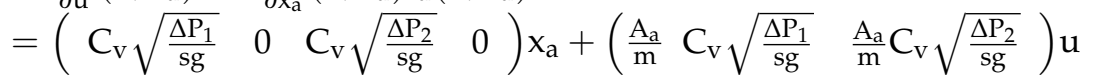

If the state vector is defined as $\mathrm{x}_{1}^{\mathrm{T}}=\left[\mathrm{x}_{11}, \mathrm{x}_{12}\right]^{\mathrm{T}}=\left[\mathrm{T}_{\mathrm{p}}, \mathrm{T}_{\mathrm{u}}\right]^{\mathrm{T}}$, the unmeasured state as $\mathrm{x}_{2}{ }^{\mathrm{T}}=\left[\mathrm{x}_{21}, \mathrm{x}_{22}\right]^{\mathrm{T}}=\left[\mathrm{u}_{\mathrm{a} 1}, \mathrm{u}_{\mathrm{a} 2}\right]^{\mathrm{T}}=\left[\mathrm{F}_{\mathrm{p}}, \mathrm{F}_{\mathrm{u}}\right]^{\mathrm{T}}$, and the output vector as $\mathrm{y}^{\mathrm{T}}=\left[\mathrm{y}_{1}, \mathrm{y}_{2}\right]^{\mathrm{T}}=\left[\mathrm{T}_{\mathrm{p}}, \mathrm{T}_{\mathrm{u}}\right]^{\mathrm{T}}$, then Equations (44) and (45) can be rewritten as

$$
\left\{\begin{array}{l}
\dot{x}_{1}=G_{1}\left(x_{1}\right) x_{2}+g_{1}\left(x_{1}, u\right) \\
\dot{x}_{2}=\varepsilon\left(u, \dot{u}, x_{a}\right) \\
y=x_{1}
\end{array}\right.
$$

where $G_{1}\left(x_{1}\right)=\left(\begin{array}{cc}\frac{\left(T_{p i}-x_{11}\right)}{V_{p}} & 0 \\ 0 & \frac{\left(T_{u i}-x_{12}\right)}{V_{u}}\end{array}\right)$ and $f_{1}(x)=\left(\begin{array}{c}\frac{h_{p} A}{\rho_{p} C_{p_{p}} V_{p}}\left(x_{11}-x_{12}\right) \\ \frac{h_{u} A}{\rho_{u} C_{p_{u}} V_{u}}\left(x_{12}-x_{11}\right)\end{array}\right)$.

\subsection{Observer Design}

\subsubsection{Observer 1 for the Actuator Subsystem}

In this model, outputs were considered as unmeasured and were substituted by its estimation proposed in Observer 2, then an extended high-gain observer of the form in Equation (26) for the system in Equation (41) is given by

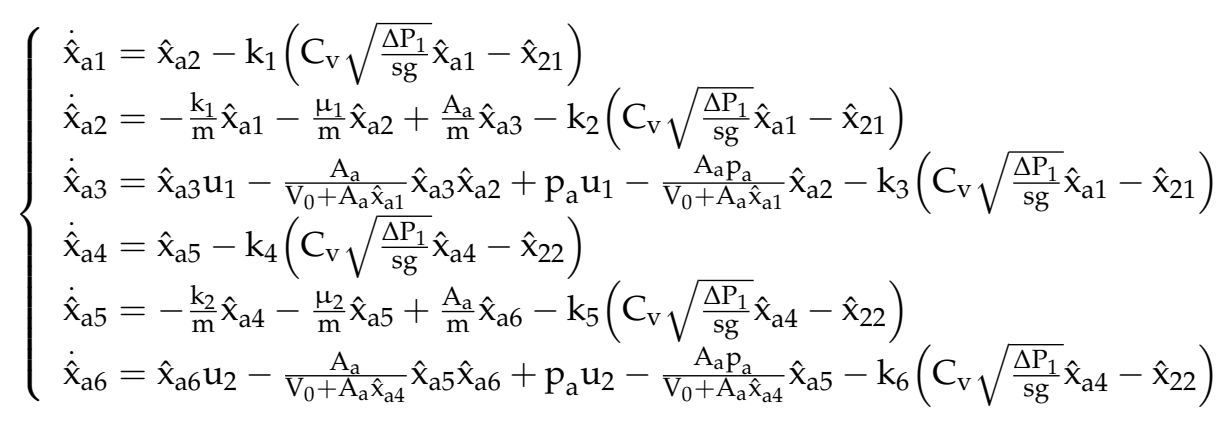

\subsubsection{Observer 2 for the Process Subsystem}

It should be noted that the original system in Equation (45) has been augmented with the differential equation $\dot{\mathrm{u}}_{\mathrm{a}}=\varepsilon\left(\mathrm{u}, \dot{\mathrm{u}}, \mathrm{x}_{\mathrm{a}}\right)$; that is to say, the unknown inputs are treated like an unmeasured state. Then, it is possible to design an observer of the form in Equation (26) for the system in Equation (46) as follows:

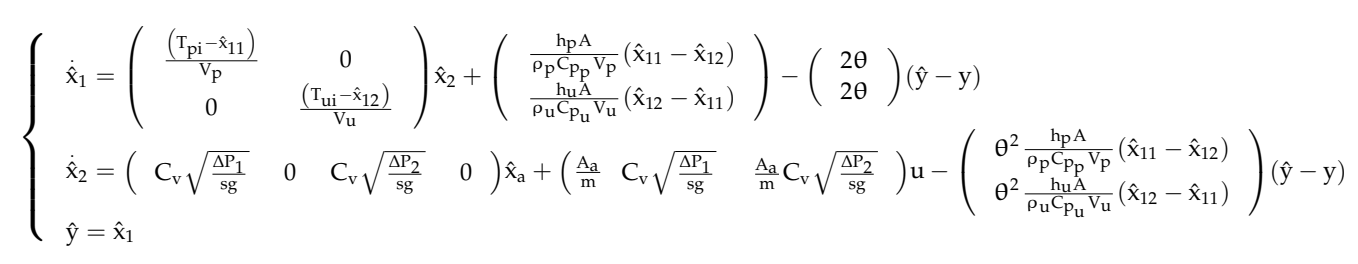

\subsection{Numerical Simulations}

In order to test the performance of the proposed observers, two numerical simulations were carried out. Considering the actuator and process models given by Equations (44) and (46), Observer 1 in Equation (47) and Observer 2 in Equation (48) were designed for estimating unmeasured inlet flows 
$F_{p}, F_{u}$ and monitoring the performance of the final products $T_{p}, T_{u}$. Available measurements involve the inlet-outlet temperatures of the hex reactor and the pneumatic pressure $\mathrm{p}_{\mathrm{c} 1}, \mathrm{p}_{\mathrm{c} 2}$ of the actuators.

Two cases were considered. In Case 1 , constant inlet flows $F_{p}, F_{u}$ were considered in both fluids. By contrast, in Case 2, $\mathrm{F}_{\mathrm{p}}, \mathrm{F}_{\mathrm{u}}$ were considered to be time varying. Observers 1 and 2 were simulated with respect to the actuator and process subsystems, using the values corresponding to an IHEX system from [17]. The parameters in the process subsystem were as follows: $\mathrm{hA}=214.8 \mathrm{~W} \cdot \mathrm{K}^{-1}, \mathrm{~V}_{\mathrm{p}}=2.685 \times 10^{-5} \mathrm{~m}^{3}, \mathrm{~V}_{\mathrm{u}}=1.141 \times 10^{-4} \mathrm{~m}^{3}$, and the inlet temperatures $\mathrm{T}_{\mathrm{pi}}$ and $\mathrm{T}_{\mathrm{ui}}$ were $76^{\circ} \mathrm{C}$ and $15^{\circ} \mathrm{C}$, respectively. The parameters in the actuator subsystem were as follows: $\mathrm{m}=2 \mathrm{~kg}, \mathrm{~A}_{\mathrm{a}}=0.029 \mathrm{~m}^{2}, \mu=1500 \mathrm{Ns} / \mathrm{m}, \mathrm{k}=6089 \mathrm{Ns} / \mathrm{m}$, Pc for the utility fluid was $1 \mathrm{MPa}(1.2 \mathrm{Mpa}$ for the process fluid), and the pressure drop $\Delta \mathrm{P}$ in the utility fluid was $0.6 \mathrm{MPa}(60 \mathrm{KPa}$ in the process fluid).

In order to illustrate the robustness, external disturbances and measurement noise were considered. Suppose the output measurement is corrupted by a colored noise. In addition to noise, no error is assumed in measuring $\mathrm{T}_{\mathrm{p}}$ and $\mathrm{T}_{\mathrm{u}}$. Moreover, to compare the effectiveness of the proposed method with other existing ones, we employed a typical unknown input observer (UIO) in [31] to show the differences.

\subsubsection{Case 1: Both Fluid Flow Rates $F_{p}, F_{u}$ Are Constant}

The objective of this simulation was to prove the convergence of the observers in a common situation where both fluid flow rates remained constant over a long time. The computed inlet flow rate of the utility fluid $\mathrm{F}_{\mathrm{u}}$ was $4.22 \times 10^{-5} \mathrm{~m}^{3} \mathrm{~s}^{-1}$, and the inlet flow rate of the process fluid $\mathrm{F}_{\mathrm{p}}$ was a constant $4.17 \times 10^{-6} \mathrm{~m}^{3} \mathrm{~s}^{-1}$. The computed value meant the expected true values of the actuators. The initial conditions of the process model were $\mathrm{T}_{\mathrm{p}}^{0}=80^{\circ} \mathrm{C}$ and $\mathrm{T}_{\mathrm{u}}^{0}=20^{\circ} \mathrm{C}$, respectively, and for the observers they were $\hat{\mathrm{T}}_{\mathrm{p}}^{0}=\hat{\mathrm{T}}_{\mathrm{u}}^{0}=30$. The discrepancies between the initial conditions of the process and those of the observers were reasonable and realistic, considering that the temperature was a process variable that could be easily measured. In order to evaluate the observer performance against uncertainties of the knowledge of the fluid flow rate, the initial value of the estimates were $\hat{\mathrm{F}}_{\mathrm{p}}^{0}=\hat{\mathrm{F}}_{\mathrm{u}}^{0}=0$ in both observers. This assumption represented a relatively rough situation in the practical engineering world. However, simulation results showed encouraging results. The tuning parameters were $\mathrm{k}_{1}=\mathrm{k}_{3}=100, \mathrm{k}_{2}=\mathrm{k}_{4}=0.15$ (for Observer 1) and $\theta=80$ (for Observer 2).

The results are reported in Figures 3 and 4. In Figure 3, the dashed curves correspond to the estimates using Observer 1, and the solid lines are the measured temperatures. It can be seen that, whether noise-free or noise-corrupted, the convergence of the estimated $\hat{\mathrm{T}}_{\mathrm{p}}$ and $\hat{\mathrm{T}}_{\mathbf{u}}$ values proved to be fast (in several seconds). It is not surprising because, actually, $\mathrm{T}_{\mathrm{p}}$ and $\mathrm{T}_{\mathrm{u}}$ were the measured outputs of the overall system.

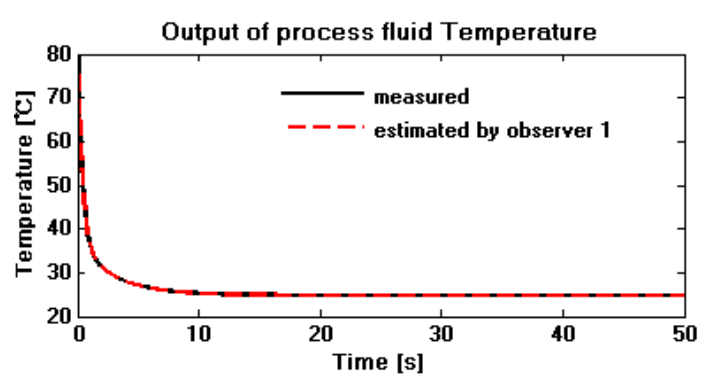

(a) Noise-free

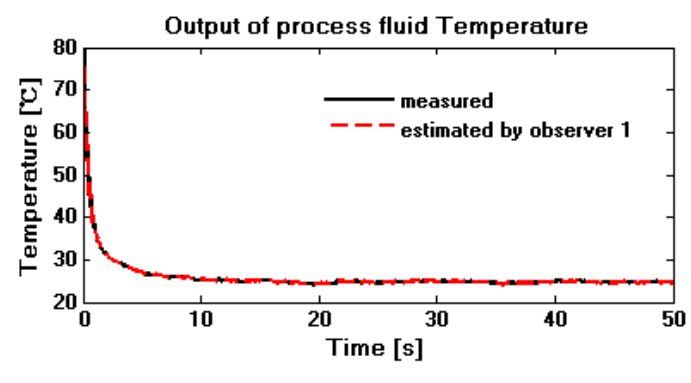

(b) Noise-corrupted

Figure 3. Output of the process fluid temperature $T_{p}$. The solid line is the measured value, and the dashed line is estimated by Observer 1. (a) represents Noise-free case while (b) represents Noise-corrupted case. 


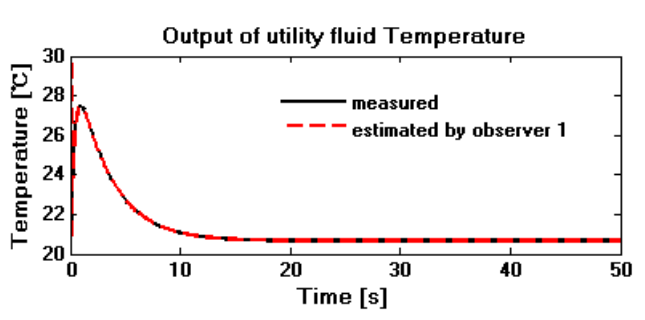

(a) Noise-free

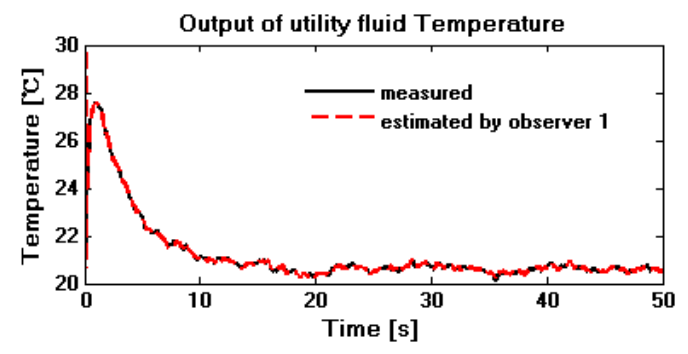

(b) Noise-corrupted

Figure 4. Output of the utility fluid temperature $T_{u}$. The solid line is the measured value, and the dashed line is estimated by Observer 1. (a) represents Noise-free case while (b) represents Noise-corrupted case.

The main contribution of the proposed method is the capacity that, besides states, it can estimate the unknown connection of an interconnected system by the final measured outputs, where the unknown connection represents the inlet fluid flow rate $F_{p}, F_{u}$ in the IHEX system. Figures 5 and 6 give the encouraging results. Figure 5 shows the computation and estimation of the process fluid flow rate $F_{p}$, using a UIO and Observer 2. Figure 6 is the results for the utility fluid flow rate $F_{u}$. As expected, $\hat{\mathrm{F}}_{\mathrm{p}}$ and $\hat{\mathrm{F}}_{\mathrm{u}}$ follow different trajectories before they converge toward the true value (computed value) in a relatively short transient period, whether or not noise exists. However, the convergence speed of the proposed method is obviously faster than that of the UIO. In addition, the proposed observer was more robust with noise. For $\mathrm{F}_{\mathrm{p}}$, as shown in Figure 5, if no noise was present, after less than $5 \mathrm{~s}$, the three curves overlapped. Compared with the curve of the UIO on the dashed, dotted line, the curve of the proposed Observer 2 in dashed, dotted line only needed less than $1 \mathrm{~s}$ to track the simulated curve of the solid line. Moreover, from Figure 5, we can see that the curve of the UIO in the dashed line was significantly more affected by noise than that of Observer 2 in the dashed, dotted line. The similar results are shown in Figure 6 with respect to $F_{u}$. According to Figure 6, it took about $1.5 \mathrm{~s}$ for the three curves to be overlapped, while for the curve of Observer 2 on the dashed line, less than $0.5 \mathrm{~s}$ was taken. The impact of noise is relatively obvious on the curve of the UIO, while for the curve of Observer 2, the influence was less significant.
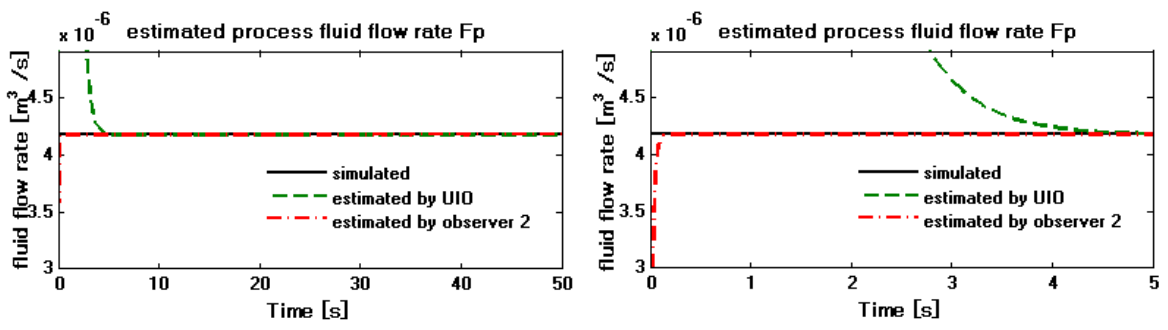

(a) Noise-free

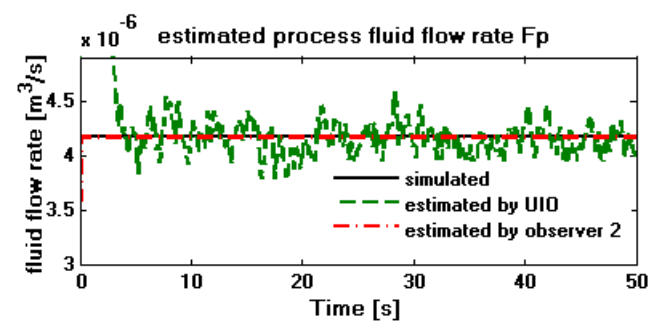

(b) Noise-corrupted

Figure 5. The computation and estimation of the process fluid flow rate $F_{p}$. The solid line is the computed value; the dashed line is estimated by the unknown input observer (UIO); and the dashed, dotted line is estimated by Observer 2. (a) represents Noise-free case while (b) represents Noise-corrupted case. 

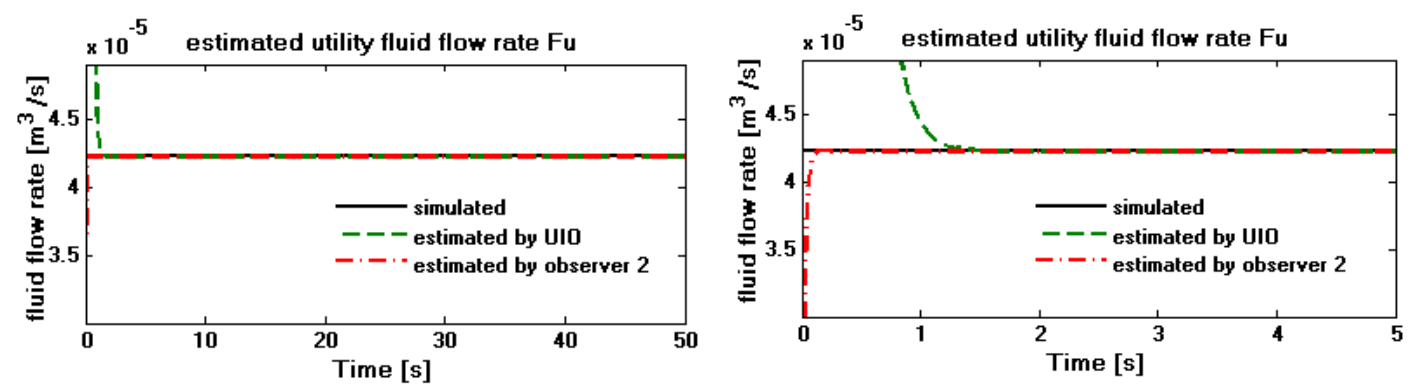

(a) Noise-free

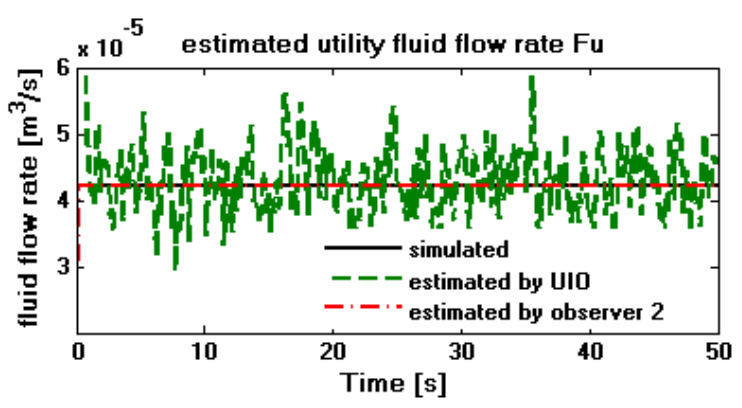

(b) Noise-corrupted

Figure 6. The computation and estimation of the utility fluid flow rate $F_{u}$. The solid line is the computed value; the dashed line is estimated by the UIO; and the dashed, dotted line is estimated by Observer 2. (a) represents Noise-free case while (b) represents Noise-corrupted case.

In both fluids, these differences were caused by their varied initial values. However, it is proven that if adequate values of the tuning parameters $\mathrm{k}$ and $\theta$ are selected, no matter the degree of deviation of the initial value of $\hat{\mathrm{F}}_{\mathrm{p}}^{0}$ and $\hat{\mathrm{F}}_{\mathrm{u}}^{0}$ from the simulated values in the system model, convergences are guaranteed. Larger values of these tuning parameters ensure a smaller convergence time, while smaller values have the opposite effect. However, large tuning values should be avoided, since the observer may become too sensitive to measurement noise in real-time applications. According to the above analysis, we can readily conclude that the proposed interconnected observer works effectively and robustly for the designed purposes with proper tuning parameters.

\subsubsection{Case 2: The Fluid Flow Rates Vary Due to Parameter Changes}

The present computations were executed to get an accurate screening of the variation of the observer estimate by corroborating if they were in agreement with the simulated fluid flow rates which underwent either an abrupt change or a gradual variation due to, for example, aging or erosion.

The parameter effects were taken into account in the following way. Initial values of $\mathrm{F}_{\mathrm{u}}=4.22 \times 10^{-5} \mathrm{~m}^{3} \mathrm{~s}^{-1}$ and $\mathrm{F}_{\mathrm{p}}=4.17 \times 10^{-6} \mathrm{~m}^{3} \mathrm{~s}^{-1}$ are considered, followed by an abrupt change of $\mathrm{F}_{\mathrm{u}}$ at $80 \mathrm{~s}$. The reason for this change is the variation of parameter $\Delta \mathrm{P}$, with the value changing from $0.6 \mathrm{MPa}$ to $0.4 \mathrm{Mpa}$. Several factors can be attributed to this kind of variation, such as valve clogging or an unexpected pressure drop across the control valves. After that, at $t=150 \mathrm{~s}, \mathrm{~F}_{\mathrm{p}}$ began to deteriorate due to an increase of the spring compliance $k_{2}$ in the process fluid actuator. One main reason contributing to this change is erosion. Because of erosion, the gland packing of the valve may loosen, which leads to stem vibration. In the simulation, a value of $1000 \mathrm{~nm}^{-1}$ was added to the spring compliance $\mathrm{k}_{2}$. This simulation was carried out using the same constants used in the previous simulation and the same values of $\mathrm{T}_{\mathrm{pi}}$ and $\mathrm{T}_{\mathrm{ui}}$, as well as $\mathrm{T}_{\mathrm{p}}^{0}$ and $\mathrm{T}_{\mathrm{u}}^{0}$, were used. The initial conditions of both observers, as well as the observer parameters $\left(\mathrm{k}_{1}, \mathrm{k}_{2}, \mathrm{k}_{3}, \mathrm{k}_{4}\right.$, and $\left.\theta\right)$ were the same as the previous ones. These variations are illustrated in Figures 7-10. 

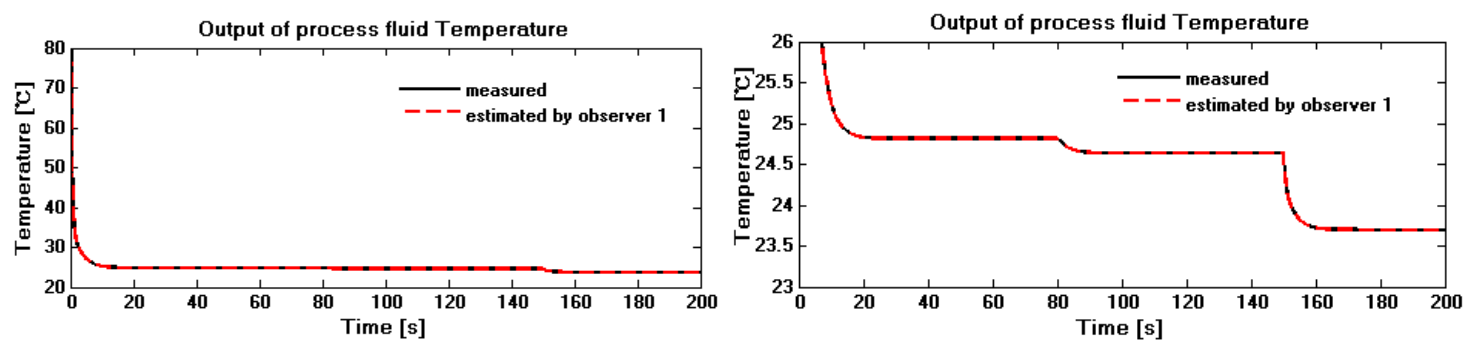

(a) Noise-free
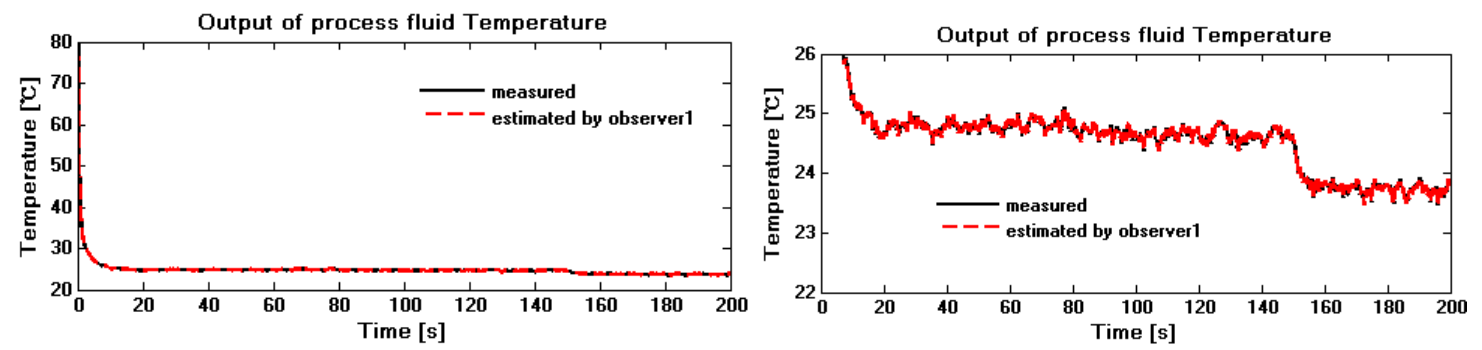

(b) Noise-corrupted

Figure 7. Outlet temperature of the process fluid $T_{p}$. The solid line is the measured value, and the dashed line is estimated by Observer 1. (a) represents Noise-free case while (b) represents Noise-corrupted case.
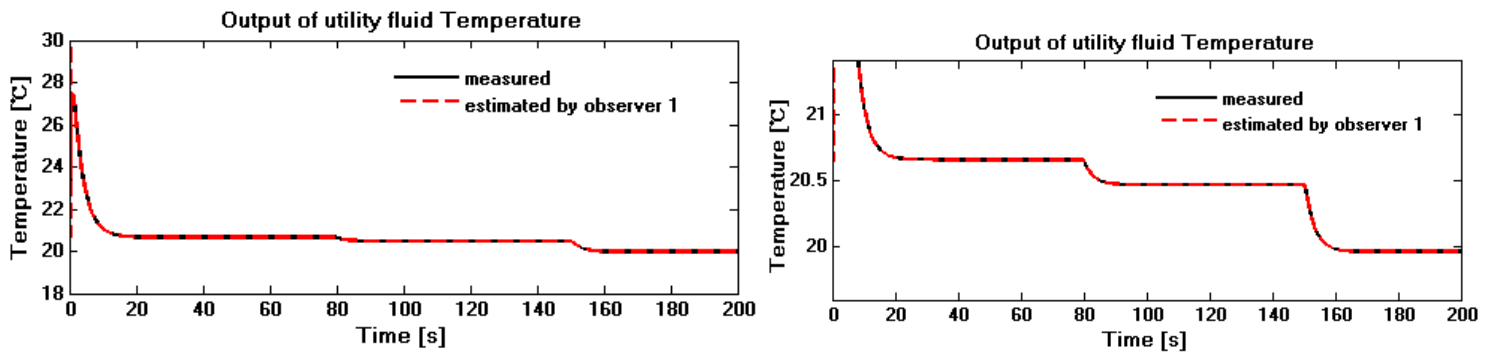

(a) Noise-free
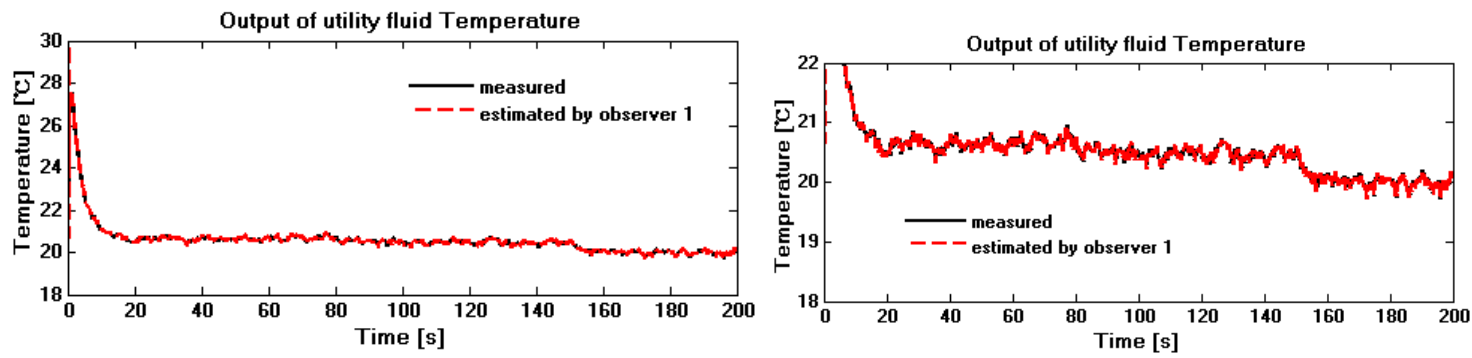

(b) Noise-corrupted

Figure 8. Outlet temperature of the utility fluid $\mathrm{T}_{\mathrm{u}}$. The solid line is the measured value, and the dashed line is estimated by Observer 1. (a) represents Noise-free case while (b) represents Noise-corrupted case. 

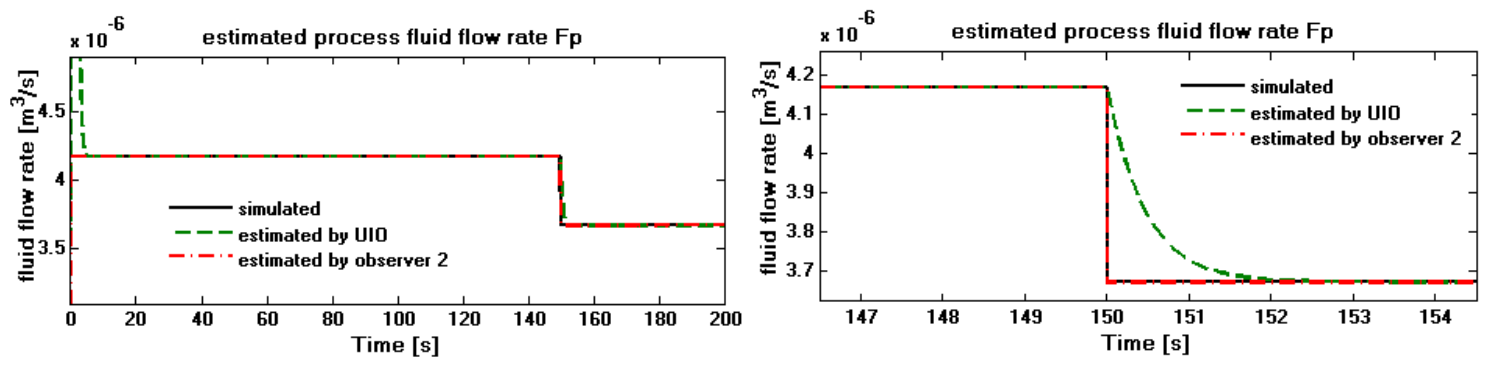

(a) Noise-free

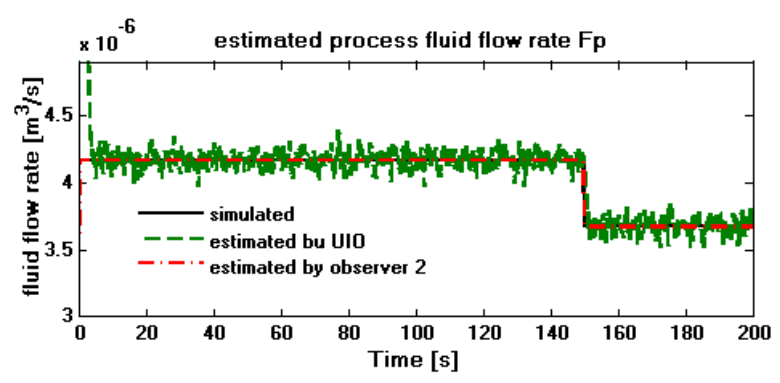

(b) Noise-corrupted

Figure 9. The computation and estimation of the process fluid flow rate $F_{p}$. The solid line is the computed value; the dashed line is estimated by the UIO; and the dashed, dotted line is estimated by Observer 2. (a) represents Noise-free case while (b) represents Noise-corrupted case.
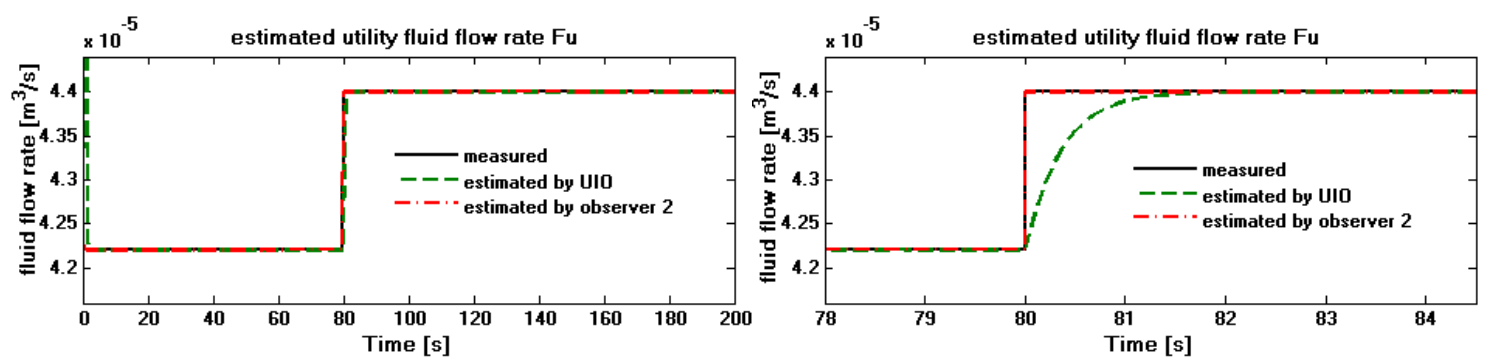

(a) Noise-free

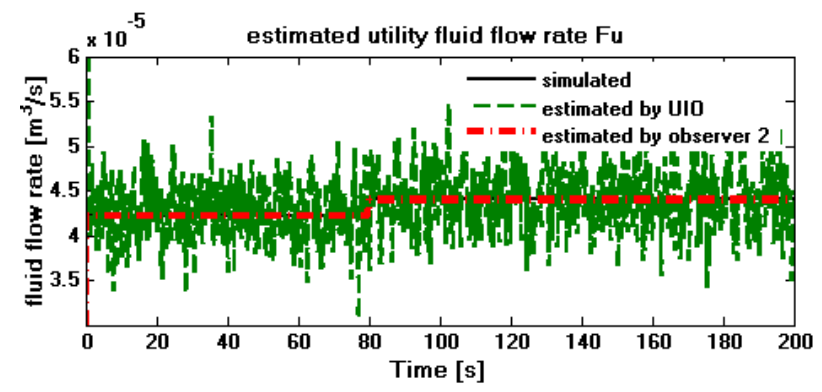

(b) Noise-corrupted

Figure 10. The computation and estimation of the utility fluid flow rate $\mathrm{F}_{\mathrm{u}}$. The solid line is the computed value; the dashed line is estimated by the UIO; and the dashed, dotted line is estimated by Observer 2. (a) represents Noise-free case while (b) represents Noise-corrupted case.

As shown in Figures 7 and 8, whether in a noise-free or noise-corrupted situation, the estimated outlet fluid temperatures $\hat{T}_{p}$ and $\hat{T}_{u}$ on the dashed line can better track the curve of the measurements $\mathrm{T}_{\mathrm{p}}$ and $\mathrm{T}_{\mathrm{u}}$ on the solid line after a short transient time. At $80 \mathrm{~s}$, both curves decreased unexpectedly and finally stabilized at a new level. A drop of $0.2{ }^{\circ} \mathrm{C}$ was observed. Shortly after, at $\mathrm{t}=150 \mathrm{~s}$, 
another drop happened, and a new stable level was expected with a $0.9^{\circ} \mathrm{C}$ reduction. These decreases imply the influences of parameter changes in the fluid actuators, and no further variations illustrate the occurrence of additional changes. A similar result was obtained in the estimated $\hat{T}_{\mathfrak{u}}$ of the utility fluid in Figure 8. It is shown that, due to changes of $\Delta \mathrm{P}_{1}$ and $\mathrm{k}_{2}$, the measured $\mathrm{T}_{\mathrm{u}}$ dropped $0.2{ }^{\circ} \mathrm{C}$ and $0.5{ }^{\circ} \mathrm{C}$ at $80 \mathrm{~s}$ and $150 \mathrm{~s}$, respectively. The estimated $\hat{\mathrm{T}}_{\mathrm{u}}$ on the dashed line tracks $\mathrm{T}_{\mathrm{u}}$ after the observer converges.

The simulation curves indicate that the proposed observer was effective at tracking system performance. However, it is shown that, because of noise, the drops caused by local parameter changes at $80 \mathrm{~s}$ could not be visually observed on the global output directly. In order to analyze the influence of these changes, we have to detect it through the local dynamics supervision. Therefore, it is very meaningful to monitor both the local and global dynamics of a control system.

It can be seen from Figure 9 that, in a noise-free situation, two estimate curves on the dashed line and the dashed, dotted line converge to the simulated value $F_{p}$ of the solid line quickly after a transient response. The dashed line is the estimated process fluid flow rate $\hat{F}_{\mathrm{p}}$ produced by the UIO, and the dashed, dotted line was generated by Observer 2. Later, at $150 \mathrm{~s}$, there was an unexpected drop by the simulated $\mathrm{F}_{\mathrm{p}}$ on the solid line. Fortunately, both estimate curves responded quickly to this variation, and the curve of the UIO took $1.5 \mathrm{~s}$ to track $\mathrm{F}_{\mathrm{p}}$ again, while the curve of Observer 2 converged more quickly than that of the UIO. The decrease implies parameter changes in the process fluid actuator, which satisfy the assumption that $k_{2}$ changes at $t=150 \mathrm{~s}$. When it comes to the noise-corrupted situation, the curve of the UIO was significantly affected by the noise, although a drop at $150 \mathrm{~s}$ can still be observed. Luckily, the curve of Observer 2 was relatively robust to the noise, as it converged to the simulated value of the solid line with a minor difference compared with the noise-free situation.

Figure 10 demonstrates the results for the utility fluid. The same results were obtained in a noise-free situation at a time of $80 \mathrm{~s}$. As expected, the simulated $\mathrm{F}_{\mathrm{u}}$ of the solid line jumped due to the change of $\Delta \mathrm{P}_{1}$. The estimated value of $\hat{\mathrm{F}}_{\mathrm{u}}$ of the dashed line by the UIO and the dashed, dotted line by Observer 2 track well with the value of $\mathrm{F}_{\mathrm{u}}$ on the solid line. Just as with the process fluid situation, the convergence speed of Observer 2 was faster than that of the UIO. If measurements were corrupted by noise, the curve of Observer 2 was not obviously influenced. Conversely, the curve of the UIO was greatly impacted.

To sum up, obviously, the proposed interconnected observer is effective, even when the unknown connection is varying in time simultaneously. Therefore, the proposed observer proves its ability to monitor the performance of interconnected systems and to estimate unknown interconnections.

\section{Conclusions}

The goal of the design methodology presented in this paper was to enable or simplify observer design for systems that are otherwise difficult to handle by allowing the designer to focus on a smaller, nonlinear subsystem. That is to say, we mainly focused on observing, for example, how the change of an internal parameter at the local level affects the global output at the global level.

An interconnected observer is designed to estimate both the state and unmeasured interconnection at the local and global levels. As a result, both local and global dynamics can be observed, as well as the influence of local dynamics on global dynamics. In particular, the interconnection is not supposed to be accessible to measurement. In order to achieve this purpose, firstly, an existing observer is extended to estimate the states of the actuator subsystem. Particularly, the information of the actuator subsystem output is substituted by their estimates, achieved by the observer of the process subsystem. Secondly, a kind of extended, high-gain observer is produced to estimate the states of the process subsystem, which is subjected to a precise unknown input. The unknown input is considered a new state of the process subsystem, and it is expressed as a function of the inputs, derivatives of the inputs, and the states of the actuator subsystem. Thus, an interconnected observer is proposed by using the estimates of the states and the unmeasured interconnection, and the convergence is investigated. 
Finally, satisfactory simulation results are obtained to confirm the effectiveness and robustness of the proposed method.

In this paper, it is clear that the physical motivation for the decomposition of a control system into the actuator and the process parts is physically motivated. In this respect, for control analysis purposes, the condition for decomposition of an independent control system may be the target of future investigations, like the inverted pendulum on a cart. Another open question worth addressing is the demonstration of stability and sensitivity of the estimation error, like the use of ISS to investigate the stability of the estimation error in [32].

Author Contributions: M.Z. and Z.L. conceived and designed the study. M.Z. and Q.W. performed the observer design, carried out simulations, and wrote the original draft. B.D. and X.C. reviewed and edited the manuscript. All authors have read and agreed to the published version of the manuscript.

Funding: This research was funded by the National Natural Science Foundation of China, Grant No. 62003106 and No. 51867006, Talent Project of GZU (2018) 02. Key Lab construction project of Guizhou Province (2016) 5103.

Conflicts of Interest: The authors declare no conflict of interest.

\section{Abbreviations}

The following abbreviations are used in this manuscript:

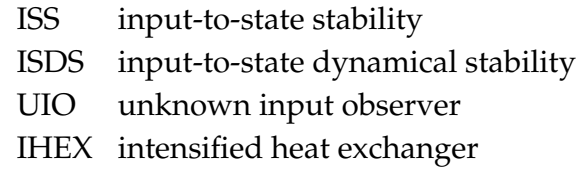

\section{Appendix A}

Proof of Theorem 1. Before preceding the convergence proof of the observer, one introduces the following notations:

$$
\mathrm{S}_{\theta}=\frac{1}{\theta} \Delta_{\theta} \mathrm{S}_{1} \Delta_{\theta}
$$

where

$$
\mathrm{S}_{1}=\mathrm{S}_{\theta \mid \theta=1} \text { and } \Delta_{\theta}=\left[\begin{array}{cc}
\mathrm{I}_{\mathrm{n}} & 0 \\
0 & \frac{1}{\theta} \mathrm{I}_{\mathrm{n}}
\end{array}\right]
$$

To proof Theorem 1 , the estimation error is introduced as $e_{p}(t)=\hat{\xi}_{1}(t)-\xi_{1}(t)$.

Then, subtracting corresponding Equations (10) and (11), one gets the following error dynamics:

$$
\begin{aligned}
\dot{e}_{\mathrm{p}} & =\mathrm{G}\left(\hat{\xi}_{11}\right) \hat{\xi}_{1}+\mathrm{F}\left(\hat{\xi}_{11}\right)+\bar{\varepsilon}\left(\mathrm{u}, \dot{\mathrm{u}}_{,} \hat{\xi}_{2}\right)+\Lambda^{-1}\left(\hat{\xi}_{1}\right) \mathrm{S}_{\theta}^{-1} \mathrm{C}^{\mathrm{T}}\left(\mathrm{C} \hat{\xi}_{1}-\mathrm{y}\right)-\mathrm{G}\left(\xi_{11}\right) \xi_{1}-\mathrm{F}\left(\xi_{11}\right)-\bar{\varepsilon}\left(\mathrm{u}, \dot{\mathrm{u}}, \xi_{2}\right) \\
& =\left(\mathrm{G}\left(\hat{\xi}_{11}\right)+\Lambda^{-1}\left(\hat{\xi}_{1}\right) \mathrm{S}_{\theta}^{-1} \mathrm{C}^{\mathrm{T}} \mathrm{C}\right) \mathrm{e}_{\mathrm{p}}+\left(\mathrm{G}\left(\hat{\xi}_{11}\right)-\mathrm{G}\left(\xi_{11}\right)\right) \xi_{1}+\mathrm{F}\left(\hat{\xi}_{11}\right)-\mathrm{F}\left(\xi_{11}\right)+\mathrm{e}_{\bar{\varepsilon}}\left(\mathrm{t}, \widetilde{\mathrm{e}}_{\mathrm{a}}\right)
\end{aligned}
$$

where $\mathrm{e}_{\bar{\varepsilon}}\left(\mathrm{t}, \widetilde{\mathrm{e}}_{\mathrm{a}}\right)=\bar{\varepsilon}\left(\mathrm{u}, \dot{\mathrm{u}}, \hat{\varepsilon}_{2}\right)-\bar{\varepsilon}\left(\mathrm{u}, \dot{\mathrm{u}}, \xi_{2}\right)$.

By setting $\widetilde{\mathrm{e}}_{\mathrm{p}}=\Delta_{\theta} \Lambda\left(\hat{\xi}_{11}\right) \mathrm{e}_{\mathrm{p}}$, one can then get

$$
\begin{gathered}
\dot{\tilde{\mathrm{e}}}_{\mathrm{p}}(\mathrm{t})=\theta\left(\mathrm{A}-\mathrm{S}_{1}^{-1} \mathrm{C}^{\mathrm{T}} \mathrm{C}\right) \widetilde{\mathrm{e}}_{\mathrm{p}}+\dot{\Lambda}\left(\hat{\xi}_{11}\right) \Lambda^{-1}\left(\hat{\xi}_{11}\right) \widetilde{\mathrm{e}}_{\mathrm{p}}+\Delta_{\theta} \Lambda\left(\hat{\xi}_{11}\right)\left(\mathrm{F}\left(\hat{\xi}_{11}\right)-\mathrm{F}\left(\xi_{11}\right)\right) \\
+\Delta_{\theta} \Lambda\left(\hat{\xi}_{11}\right) \mathrm{G}\left(\hat{\xi}_{11}\right) \xi_{1}-\mathrm{G}\left(\xi_{11}\right) \xi_{1}-\Delta_{\theta} \Lambda\left(\hat{\xi}_{11}\right) \mathrm{e}_{\bar{\varepsilon}}\left(\mathrm{t}, \widetilde{\mathrm{e}}_{\mathrm{a}}\right)
\end{gathered}
$$

To analyze the dynamics of the error system, the following positive Lyapunov function candidate is considered:

$$
\mathrm{V}_{\mathrm{p}}\left(\mathrm{t}, \widetilde{\mathrm{e}}_{\mathrm{p}}\right)=\widetilde{\mathrm{e}}_{\mathrm{p}}^{\mathrm{T}} \mathrm{S}_{1} \widetilde{\mathrm{e}}_{\mathrm{p}}
$$


Convergence of the observer is described by the time derivation of $\mathrm{V}_{\mathrm{p}}\left(\mathrm{t}, \widetilde{\mathrm{e}}_{\mathrm{p}}\right)$. Then, we obtain

$$
\begin{aligned}
& \dot{\mathrm{V}}_{\mathrm{p}}\left(\mathrm{t}, \widetilde{\mathrm{e}}_{\mathrm{p}}\right)=2 \widetilde{\mathrm{e}}_{\mathrm{p}}^{\mathrm{T}} \mathrm{S}_{1} \dot{\widetilde{\mathrm{e}}}_{\mathrm{p}} \\
& =\theta\left(2 \widetilde{\mathrm{e}}_{\mathrm{p}}^{\mathrm{T}} \mathrm{S}_{1} A \widetilde{\mathrm{e}}_{\mathrm{p}}-2 \widetilde{\mathrm{e}}_{\mathrm{p}}^{\mathrm{T}} \mathrm{C}^{\mathrm{T}} \mathrm{C} \widetilde{\mathrm{e}}_{\mathrm{p}}\right)+2 \widetilde{\mathrm{e}}_{\mathrm{p}}^{\mathrm{T}} \mathrm{S}_{1} \dot{\Lambda}\left(\hat{\xi}_{11}\right) \Lambda^{-1}\left(\hat{\xi}_{11}\right) \widetilde{\mathrm{e}}_{\mathrm{p}} \\
& +2 \widetilde{\mathrm{e}}_{\mathrm{p}}^{\mathrm{T}} \mathrm{S}_{1} \Delta_{\theta} \Lambda\left(\hat{\xi}_{11}\right)\left(\mathrm{F}\left(\hat{\xi}_{11}\right)-\mathrm{F}\left(\xi_{11}\right)\right) \\
& +2 \widetilde{\mathrm{e}}_{\mathrm{p}}^{\mathrm{T}} \mathrm{S}_{1} \Delta_{\theta} \Lambda\left(\hat{\varepsilon}_{11}\right)\left(\left(\mathrm{G}\left(\hat{\varepsilon}_{11}\right)-\mathrm{G}\left(\xi_{11}\right)\right) \xi_{1}\right)-2 \widetilde{\mathrm{e}}_{\mathrm{p}}^{\mathrm{T}} \mathrm{S}_{1} \Delta_{\theta} \Lambda\left(\hat{\varepsilon}_{11}\right) \mathrm{e}_{\bar{\varepsilon}}\left(\mathrm{t}, \widetilde{\mathrm{e}}_{\mathrm{a}}\right) \\
& =-\theta \mathrm{V}_{\mathrm{p}}-\theta\left\|C \widetilde{\mathrm{e}}_{\mathrm{p}}\right\|^{2}+2 \widetilde{\mathrm{e}}_{\mathrm{p}}^{\mathrm{T}} \mathrm{S}_{1} \dot{\Lambda}\left(\hat{\xi}_{11}\right) \Lambda^{-1}\left(\hat{\xi}_{11}\right) \widetilde{\mathrm{e}} \mathrm{p}+2 \widetilde{\mathrm{e}}_{\mathrm{p}}^{\mathrm{T}} \mathrm{S}_{1} \Delta_{\theta} \Lambda\left(\hat{\xi}_{11}\right)\left(\mathrm{F}\left(\hat{\xi}_{11}\right)-\mathrm{F}\left(\xi_{11}\right)\right) \\
& +2 \widetilde{\mathrm{e}}_{\mathrm{p}}^{\mathrm{T}} \mathrm{S}_{1} \Delta_{\theta} \Lambda\left(\hat{\varepsilon}_{11}\right)\left(\left(\mathrm{G}\left(\hat{\xi}_{11}\right)-\mathrm{G}\left(\xi_{11}\right)\right) \xi_{1}\right)-2 \widetilde{\mathrm{e}}_{\mathrm{p}}^{\mathrm{T}} \mathrm{S}_{1} \Delta_{\theta} \Lambda\left(\hat{\xi}_{11}\right) \mathrm{e}_{\bar{\varepsilon}}\left(\mathrm{t}, \widetilde{\mathrm{e}}_{\mathrm{a}}\right) \\
& \leq-\theta \mathrm{V}_{\mathrm{p}}+2\left\|\mathrm{~S}_{1} \widetilde{\mathrm{e}}_{\mathrm{p}}\right\|\left\|\dot{\Lambda}\left(\hat{\xi}_{11}\right) \Lambda^{-1}\left(\hat{\xi}_{11}\right)\right\|\left\|\widetilde{\mathrm{e}}_{\mathrm{p}}\right\|+2\left\|\mathrm{~S}_{1} \widetilde{\mathrm{e}}_{\mathrm{p}}\right\|\left\|\Lambda\left(\hat{\xi}_{11}\right)\right\|\left\|\Delta_{\theta}\left(\mathrm{F}\left(\hat{\xi}_{11}\right)-\mathrm{F}\left(\xi_{11}\right)\right)\right\| \\
& +2\left\|S_{1} \widetilde{\mathrm{e}}_{\mathrm{p}}\right\|\left\|\Delta_{\theta} \Lambda\left(\hat{\xi}_{11}\right)\left(\left(\mathrm{G}\left(\hat{\xi}_{11}\right)-\mathrm{G}\left(\xi_{11}\right)\right) \xi_{1}\right)\right\|+\frac{2}{\theta}\left\|\mathrm{S}_{1} \widetilde{\mathrm{e}}_{\mathrm{p}}\right\|\left\|\mathrm{G}\left(\hat{\xi}_{11}\right)\right\|\left\|\mathrm{e}_{\bar{\varepsilon}}\left(\mathrm{t}, \widetilde{\mathrm{e}}_{\mathrm{a}}\right)\right\| \\
& \leq-\theta \mathrm{V}_{\mathrm{p}}+2 \mu\left\|\mathrm{S}_{1} \widetilde{\mathrm{e}}_{\mathrm{p}}\right\|\left\|\widetilde{\mathrm{e}}_{\mathrm{p}}\right\|+2 \rho\left\|\mathrm{S}_{1} \widetilde{\mathrm{e}}_{\mathrm{p}}\right\|\left\|\Delta_{\theta}\left(\mathrm{F}\left(\hat{\xi}_{11}\right)-\mathrm{F}\left(\xi_{11}\right)\right)\right\| \\
& +2\left\|S_{1} \widetilde{\mathrm{e}}_{\mathrm{p}}\right\|\left\|\Delta_{\theta} \Lambda\left(\hat{\xi}_{11}\right)\left(\left(\mathrm{G}\left(\hat{\xi}_{11}\right)-\mathrm{G}\left(\xi_{11}\right)\right) \xi_{1}\right)\right\|+\frac{2 \tau \gamma_{1}}{\theta}\left\|\mathrm{S}_{1} \widetilde{\mathrm{e}}_{\mathrm{p}}\right\|\|\| \xi_{2}-\hat{\xi}_{2}\|\|
\end{aligned}
$$

where $\mu=\sup _{\mathbf{t} \geq 0}\left\|\dot{\Lambda}\left(\hat{\xi}_{11}\right) \Lambda^{-1}\left(\hat{\xi}_{11}\right)\right\|, \rho$ is the upper boundary of $\left\|\Lambda\left(\hat{\varepsilon}_{11}\right)\right\|,\left\|\mathrm{e}_{\bar{\varepsilon}}\left(\mathrm{t}, \widetilde{\mathrm{e}}_{\mathrm{a}}\right)\right\| \leq \gamma_{1}\left\|\xi_{2}-\hat{\xi}_{2}\right\|$, as proposed in Assumption 1, and $\tau$ is a finite real number with $0<\rho \leq \tau$, such that $\rho^{2} I_{n} \leq F^{T}\left(\xi_{11}\right) F\left(\xi_{11}\right) \leq \tau^{2} I_{n}$, as given in Assumptions 2-4.

Then, we have

$$
\left\|\Delta_{\theta}\left(\mathrm{F}\left(\hat{\xi}_{11}\right)-\mathrm{F}\left(\xi_{11}\right)\right)\right\| \leq\left\|\mathrm{f}\left(\hat{\varepsilon}_{11}\right)-\mathrm{f}\left(\xi_{11}\right)\right\| \leq \sigma\left\|\widetilde{\mathrm{e}}_{\mathrm{p}}\right\|
$$

where $\sigma$ denotes the Lipchitz constants of $\mathrm{f}\left(\xi_{11}\right)$.

Similarly, we have

$$
\left\|\Delta_{\theta} \Lambda\left(\hat{\xi}_{11}\right)\left(\left(\mathrm{G}\left(\hat{\xi}_{11}\right)-\mathrm{G}\left(\xi_{11}\right)\right) \xi_{1}\right)\right\|=\left\|\left(\left(\mathrm{g}\left(\hat{\xi}_{11}\right)-\mathrm{g}\left(\xi_{11}\right)\right) \xi_{12}\right)\right\| \leq \epsilon\left\|\widetilde{\mathrm{e}}_{\mathrm{p}}\right\|
$$

where the positive constant $\epsilon$ denotes the boundary of $\xi_{12}$.

Thus, we get the following:

$$
\begin{aligned}
\dot{\mathrm{V}}_{\mathrm{p}}\left(\mathrm{t}, \widetilde{\mathrm{e}}_{\mathrm{p}}\right) & \leq-\theta \mathrm{V}_{\mathrm{p}}+\eta_{1} \mathrm{~V}_{\mathrm{p}}+\frac{\eta_{2}}{\theta} \sqrt{\mathrm{V}_{\mathrm{p}}}\left\|\xi_{2}-\hat{\xi}_{2}\right\| \\
& \leq\left(-\theta+\eta_{1}\right) \mathrm{V}_{\mathrm{p}}+\frac{\eta_{2}}{\theta} \sqrt{\mathrm{V}_{\mathrm{p}}}\left\|\xi_{2}-\hat{\xi}_{2}\right\|
\end{aligned}
$$

where $\eta_{1}=(2 \mu+2 \rho \sigma+2 \epsilon) \xi\left(S_{1}\right)$ and $\xi\left(S_{1}\right)=\sqrt{\lambda_{\max }\left(S_{1}\right) / \lambda_{\min }\left(S_{1}\right)}, \eta_{2}=2 \tau \gamma_{1} \sqrt{\lambda_{\max }\left(S_{1}\right)} . \quad \lambda_{\max }\left(S_{1}\right)$ (resp. $\lambda_{\max }\left(S_{1}\right)$ ) is the largest (resp. the smallest) eigenvalue of $\lambda_{\max }\left(S_{1}\right)$.

Thus, the following hold true:

1. if $\left\|\xi_{2}-\hat{\xi}_{2}\right\|$ converges to 0 , it results in $\dot{V}_{p}\left(t, \widetilde{e}_{p}\right) \leq\left(-\theta+\eta_{1}\right) V_{p}$. Then, by taking $\theta>\theta^{*}=\eta_{1}$, the negative of the right side of the above inequality is obtained;

2. if $\left\|\xi_{2}-\hat{\xi}_{2}\right\|$ is bounded by $\widetilde{\mathrm{e}}_{\mathrm{p}}$, it results in $\left.\dot{\mathrm{V}}_{\mathrm{p}}\left(\mathrm{t}, \widetilde{\mathrm{e}}_{\mathrm{p}}\right) \leq\left(-\theta+\eta_{1}+\frac{\eta_{2}}{\theta}\right)\right) \mathrm{V}_{\mathrm{p}}$. Then, by choosing $\theta>\theta^{*}$ such that $\left(\theta^{*}-\eta_{1}-\frac{\eta_{2}}{\theta^{*}}\right) \geq 0$, the negative of the right side of the above inequality is obtained.

That ends the proof.

\section{Appendix B}

Proof of Theorem 2. In order to show that the system described in Equation (23) represents a converging observer for the system in Equation (18), we need to make its corresponding error dynamics in Equation (24) coincide with Assumption 6, which has been proven to be a condition for the existence of a converging observer.

$$
\begin{aligned}
\dot{\tilde{\mathrm{e}}}_{\mathrm{a}}\left(\mathrm{t}, \widetilde{\mathrm{e}}_{\mathrm{a}}\right) & =\overline{\mathrm{f}}_{2}\left(\xi_{2}, \mathrm{u}\right)-\overline{\mathrm{f}}_{2}\left(\hat{\xi}_{2}, \mathrm{u}\right)-\mathrm{K}_{2}\left(\mathrm{u}, \hat{\mathrm{\xi}}_{2}, \widetilde{\mathrm{y}}_{2}\right) \\
& =\overline{\mathrm{f}}_{2}\left(\xi_{2}, \mathrm{u}\right)-\overline{\mathrm{f}}_{2}\left(\hat{\xi}_{2}, \mathrm{u}\right)-\mathrm{K}_{2}\left(\mathrm{u}, \hat{\xi}_{2}, \mathrm{y}_{2}\right)+\mathrm{K}_{2}\left(\mathrm{u}, \hat{\xi}_{2}, \mathrm{y}_{2}\right)-\mathrm{K}_{2}\left(\mathrm{u}, \hat{\xi}_{2}, \widetilde{\mathrm{y}}_{2}\right) \\
& =\dot{\mathrm{e}}_{\mathrm{a}}\left(\mathrm{t}, \mathrm{e}_{\mathrm{a}}\right)+\mathrm{K}_{2}\left(\mathrm{u}, \hat{\xi}_{2}, \mathrm{y}_{2}\right)-\mathrm{K}_{2}\left(\mathrm{u}, \hat{\xi}_{2}, \widetilde{\mathrm{y}}_{2}\right)
\end{aligned}
$$

Therefore, by computing the time derivation of $V_{a}$ with respect to the trajectory $\widetilde{e}_{a}$ in Equation (24), using Assumptions 6 and 7, it follows that

$$
\dot{\mathrm{V}}_{\mathrm{a}}\left(\mathrm{t}, \widetilde{\mathrm{e}}_{\mathrm{a}}\right)=\frac{\partial \mathrm{V}_{\mathrm{a}}}{\partial \mathrm{t}}\left(\mathrm{t}, \mathrm{e}_{\mathrm{a}}\right)+\frac{\partial \mathrm{V}_{\mathrm{a}}}{\partial \mathrm{e}_{\mathrm{a}}}\left(\mathrm{t}, \mathrm{e}_{\mathrm{a}}\right) \dot{\mathrm{e}}_{\mathrm{a}}\left(\mathrm{t}, \mathrm{e}_{\mathrm{a}}\right)+\frac{\partial \mathrm{V}_{\mathrm{a}}}{\partial \mathrm{e}_{\mathrm{a}}}\left(\mathrm{t}, \mathrm{e}_{\mathrm{a}}\right)\left(\mathrm{K}_{2}\left(\mathrm{u}, \hat{\mathrm{\varepsilon}}_{2}, \mathrm{y}_{2}\right)-\mathrm{K}_{2}\left(\mathrm{u}, \hat{\varepsilon}_{2}, \widetilde{\mathrm{y}}_{2}\right)\right)
$$




$$
\begin{gathered}
\leq-\alpha_{2}\left\|\mathrm{e}_{\mathrm{a}}\right\|^{2}+\beta_{2} \gamma_{2}\left\|\mathrm{e}_{\mathrm{a}}\right\|\left\|\mathrm{y}_{2}-\widetilde{\mathrm{y}}_{2}\right\| \\
\leq-\alpha_{2}\left\|\mathrm{e}_{\mathrm{a}}\right\|^{2}+\eta_{3}\left\|\mathrm{e}_{\mathrm{a}}\right\|\left\|\mathrm{y}_{2}-\widetilde{\mathrm{y}}_{2}\right\|
\end{gathered}
$$

where $\eta_{3}=\beta_{2} \gamma_{2}$. Since the output $\widetilde{y}_{2}$ used in the observer in Equation (23) is in fact a virtual measurement which is estimated by the output of the process subsystem, it is in fact $\xi_{12}, \hat{\varepsilon}_{12}$.

$$
\dot{\mathrm{V}}_{\mathrm{a}}\left(\mathrm{t}, \widetilde{\mathrm{e}}_{\mathrm{a}}\right) \leq-\alpha_{2}\left\|\mathrm{e}_{\mathrm{a}}\right\|^{2}+\eta_{3}\left\|\mathrm{e}_{\mathrm{a}}\right\|\left\|\xi_{12}-\hat{\xi}_{12}\right\|
$$

Thus, the right side of this inequality is negative if the following conditions are met:

1. $\quad \alpha_{2} \geq \beta_{2} \gamma_{2}$ and $\left\|\xi_{12}-\hat{\xi}_{12}\right\|$ is bounded by $\mathbf{e}_{\mathrm{a}}$, resulting in $\dot{\mathrm{V}}_{\mathrm{a}}\left(\mathrm{t}, \widetilde{\mathrm{e}}_{\mathrm{a}}\right) \leq-\left(\alpha_{2}-\eta_{3}\right)\left\|\mathbf{e}_{\mathrm{a}}\right\|^{2}$;

2. $\quad\left\|\xi_{12}-\hat{\xi}_{12}\right\|$ converges to 0 , resulting in $\dot{V}_{a}\left(t, \widetilde{e}_{a}\right) \leq-\alpha_{2}\left\|e_{a}\right\|^{2}$.

This ends the proof.

\section{References}

1. Yang, J.; Zhu, F.; Yu, K.; Bu, X. Observer-based state estimation and unknown input reconstruction for nonlinear complex dynamical systems. Commun. Nonlinear Sci. Numer. Simul. 2015, 20, 927-939. [CrossRef]

2. Gauthier, J.; Hammouri, H.; Othman, S. A simple observer for nonlinear systems applications to bioreactors. IEEE Trans. Autom. Control. 1992, 37, 875-880. [CrossRef]

3. Bartyś, M.; Patton, R.; Syfert, M.; Heras, S.D.L.; Quevedo, J. Introduction to the DAMADICS actuator FDI benchmark study. Control. Eng. Pr. 2006, 14, 577-596. [CrossRef]

4. Moreno, J.A.; Alvarez, J. On the estimation problem of a class of continuous bioreactors with unknown input. J. Process. Control. 2015, 30, 34-49. [CrossRef]

5. De Persis, C.; Isidori, A. A geometric approach to nonlinear fault detection and isolation. IEEE Trans. Autom. Control. 2001, 45, 853-865. [CrossRef]

6. Zhu, F. State estimation and unknown input reconstruction via both reduced-order and high-order sliding mode observers. J. Process. Control. 2012, 22, 296-302. [CrossRef]

7. Besançon, G. Remarks on nonlinear adaptive observer design. Syst. Control. Lett. 2000, 41, 271-280. [CrossRef]

8. Vijay, P.; Tadé, M.O.; Ahmed, K.; Utikar, R.; Pareek, V.K. Simultaneous estimation of states and inputs in a planar solid oxide fuel cell using nonlinear adaptive observer design. J. Power Sources 2014, 248, 1218-1233. [CrossRef]

9. Li, Z.; Dahhou, B. A new fault isolation and identification method for nonlinear dynamic systems: Application to a fermentation process. Appl. Math. Model. 2008, 32, 2806-2830. [CrossRef]

10. Pan, S.; Xiao, D.; Xing, S.; Law, S.; Du, P.; Li, Y. A general extended Kalman filter for simultaneous estimation of system and unknown inputs. Eng. Struct. 2016, 109, 85-98. [CrossRef]

11. Manaa, I.; Barhoumi, N.; M'Sahli, F. Unknown inputs observers design for a class of nonlinear switched systems. Int. J. Model. Identif. Control. 2015, 23, 45. [CrossRef]

12. Besançon, G.; Munteanu, I. Control strategy for state and input observer design. Syst. Control. Lett. 2015, 85, 118-122. [CrossRef]

13. Guo, S.; Zhu, F. Actuator fault detection and interval reconstruction based on interval observers. IFAC-PapersOnLine 2017, 50, 5061-5066. [CrossRef]

14. Buciakowski, M.; Witczak, M.; Puig, V.; Rotondo, D.; Nejjari, F.; Korbicz, J. A bounded-error approach to simultaneous state and actuator fault estimation for a class of nonlinear systems. J. Process. Control. 2017, 52, 14-25. [CrossRef]

15. Vijay, P.; Tadé, M.O. An adaptive non-linear observer for the estimation of temperature distribution in the planar solid oxide fuel cell. J. Process. Control. 2013, 23, 429-443. [CrossRef]

16. Marzat, J.; Piet-Lahanier, H.; Damongeot, F.; Walter, É. Fault diagnosis for nonlinear aircraft based on control-induced redundancy. In Proceedings of the SysTol 2010: Conference on Control and Fault-Tolerant Systems, Nice, France, 6-8 October 2010; pp. 119-124. 
17. Théron, F.; Anxionnaz-Minvielle, Z.; Cabassud, M.; Gourdon, C.; Tochon, P. Characterization of the performances of an innovative heat-exchanger/reactor. Chem. Eng. Process. Process. Intensif. 2014, 82, 30-41. [CrossRef]

18. Zhang, M.; Li, Z.-T.; Cabassud, M.; Dahhou, B. Root cause analysis of actuator fault based on invertibility of interconnected system. Int. J. Model. Identif. Control. 2017, 27, 256. [CrossRef]

19. Zou, T.; Wu, S.; Zhang, R. Improved state space model predictive fault-tolerant control for injection molding batch processes with partial actuator faults using GA optimization. ISA Trans. 2018, 73, 147-153. [CrossRef]

20. Kadlec, P.; Gabrys, B.; Strandt, S. Data-driven Soft Sensors in the process industry. Comput. Chem. Eng. 2009, 33, 795-814. [CrossRef]

21. Boccaletti, S.; Latora, V.; Moreno, Y.; Chavez, M.; Hwang, D. Complex networks: Structure and dynamics. Phys. Rep. 2006, 424, 175-308. [CrossRef]

22. Keliris, C.; Polycarpou, M.M.; Parisini, T. A robust nonlinear observer-based approach for distributed fault detection of input-output interconnected systems. Automatica 2015, 53, 408-415. [CrossRef]

23. Gao, N.; Darouach, M.; Alma, M.; Voos, H. Decentralized dynamic-observer-based control for large scale nonlinear uncertain systems. In Proceedings of the 2015 American Control Conference (ACC), Chicago, IL, USA, 1-3 July 2015; pp. 4131-4136.

24. Li, Y.; Sanfelice, R.G. Interconnected Observers for Robust Decentralized Estimation With Performance Guarantees and Optimized Connectivity Graph. IEEE Trans. Control. Netw. Syst. 2015, 3, 1-11. [CrossRef]

25. Chakrabarty, A.; Sundaram, S.; Corless, M.J.; Buzzard, G.T.; Żak, S.H.; Rundell, A.E. Distributed unknown input observers for interconnected nonlinear systems. In Proceedings of the 2016 American Control Conference (ACC), Boston, MA, USA, 6-8 July 2016; pp. 101-106.

26. Besançon, G.; Hammouri, H. On observer design for interconnected systems. J. Math. Syst. Estim. Control 1998, 8, 1-26.

27. Dashkovskiy, S.; Naujok, L. Quasi-ISS/ISDS observers for interconnected systems and applications. Syst. Control. Lett. 2015, 77, 11-21. [CrossRef]

28. Ahmed-Ali, T.; Giri, F.; Krstic, M.; Lamnabhi-Lagarrigue, F. Observer design for a class of nonlinear ODE-PDE cascade systems. Syst. Control. Lett. 2015, 83, 19-27. [CrossRef]

29. Grip, H.F.; Saberi, A.; Johansen, T.A. Observers for interconnected nonlinear and linear systems. Automatica 2012, 48, 1339-1346. [CrossRef]

30. Farza, M.; Busawon, K.; Hammouri, H. Simple nonlinear observers for on-line estimation of kinetic rates in bioreactors. Automatica 1998, 34, 301-318. [CrossRef]

31. Zhang, M.; Li, Z.-T.; Cabassud, M.; Dahhou, B. Unknown input reconstruction: A comparison of system inversion and sliding mode observer based techniques. In Proceedings of the CCC2017 (2017 Chinese Control Conference), Daian, China, 26-27 July 2017; pp. 7172-7177.

32. Alessandri, A.; Bagnerini, P.; Cianci, R. State observation for Lipchitz nonlinear dynamical systems basen on Lyapunov functions and functionals. Mathematics 2020, 8, 1424. [CrossRef]

Publisher's Note: MDPI stays neutral with regard to jurisdictional claims in published maps and institutional affiliations.

(C) 2020 by the authors. Licensee MDPI, Basel, Switzerland. This article is an open access article distributed under the terms and conditions of the Creative Commons Attribution (CC BY) license (http://creativecommons.org/licenses/by/4.0/). 